Check for updates

Cite this: RSC Adv., 2019, 9, 22248

\title{
Single-step synthesis of eucalyptus sawdust magnetic activated carbon and its adsorption behavior for methylene blue
}

\author{
Congjin Chen, (D) *ab Shuai Mi, ${ }^{\mathrm{b}}$ Dongmei Lao, ${ }^{\mathrm{b}}$ Panpan Shi, ${ }^{\mathrm{b}}$ Zhangfa Tong, (D) ${ }^{\mathrm{a}}$ \\ Zhixia $\mathrm{Li}^{\mathrm{b}}$ and Huayu $\mathrm{Hu}^{\mathrm{b}}$
}

Eucalyptus wood-based magnetic activated carbon (MAC) was prepared using single-step carbonization activation magnetization with $\mathrm{FeCl}_{3}$ and utilized for the adsorption of methylene blue (MB). The MAC was prepared using the following conditions: the mass ratio of $\mathrm{FeCl}_{3}$ to eucalyptus sawdust was controlled to $2: 1$, the one-step carbonated activated magnetization temperature and time was $700{ }^{\circ} \mathrm{C}$ and $75 \mathrm{~min}$. The prepared MAC was evaluated for textural characteristics such as the adsorption capacity, pore structure, surface chemical functional groups, magnetic properties, microcrystalline structure, and the surface morphology using the test methods described in the National Standard of China, these were $\mathrm{N}_{2}$-adsorption-desorption isotherms, Fourier transform infrared spectroscopy (FTIR), value stream mapping (VSM), X-ray diffraction (XRD) and scanning electron microscopy (SEM). Batch experiments were carried out to evaluate the adsorption behavior of MB on the prepared MAC at different temperatures of 298-328 K and MB initial concentration of $50.0-500.0 \mathrm{mg} \mathrm{L}^{-1}$. The results were as follows: the iodine number, methylene blue adsorption and phenol adsorption of the prepared MAC were 473.14, 228.22 and $70.90 \mathrm{mg} \mathrm{g}^{-1}$, respectively; MAC exhibited a microporous and mesoporous structure with a mesoporosity of $36 \%$, the BET specific surface area, average pore diameter and pore volume were $645.23 \mathrm{~m}^{2} \mathrm{~g}^{-1}, 2.71 \mathrm{~nm}$ and $0.44 \mathrm{~cm}^{3} \mathrm{~g}^{-1}$, respectively, and for the magnetic parameters the following results were found, a $H_{c}$ of $108.51 \mathrm{Oe}, M_{s}$ of $30.37 \mathrm{emu} \mathrm{g}^{-1}$ and $M_{r}$ of 2.46 emu $\mathrm{g}^{-1}$; there were $\mathrm{OH}, \mathrm{C}-\mathrm{O}, \mathrm{C}=\mathrm{O}, \mathrm{C}=\mathrm{C}, \mathrm{COO}, \mathrm{C}-\mathrm{N}$, and $\mathrm{Fe}-\mathrm{O}$ groups on the MAC surface, and $\mathrm{Fe}_{3} \mathrm{O}_{4}$ existed in the pores and surfaces of the MAC. The MB adsorption on the MAC followed the Langmuir isotherm and Dubinin-Radushkevich isotherm model, the adsorption process was a spontaneous, endothermic chemisorption progress, followed by the pseudo-second-order model, and the adsorption process was influenced by multiple diffusion steps, the pore diffusion process was the rate-controlling step, however, the adsorption process was also affected by the film diffusion and surface adsorption. The results reveal that MAC efficiently adsorbs MB and can be easily separated and recovered by an external magnetic field. The as-prepared MAC could be used as a potential adsorbent for organic pollutant wastewater treatment.

Received 9th May 2019

Accepted 18th June 2019

DOI: $10.1039 / \mathrm{c} 9 \mathrm{ra03490k}$

rsc.li/rsc-advances of waste water ${ }^{5}$ and waste gas ${ }^{6}$ produced by industrial manufacturers or daily activities. With the increasing shortage of water, it is important to protect water resources ${ }^{7}$ and control water pollution effectively. Printing and dyeing wastewater ${ }^{8}$ is one of the main sources of industrial water pollution and has a higher chrominance and organic content, which is complicated in terms of chemical composition ${ }^{9}$ and is difficult to deal with. There is a continuous demand to remove dye efficiently from aqueous solutions and reduce the concentration to below the discharge threshold limits. ${ }^{10}$ Compared with other methods of water pollution control, such as coagulation/flocculation, advanced oxidation processes, ozonation, membrane filtration and biological treatment, ${ }^{11}$ adsorption is considered to be a high efficient, green, low cost and easy to use procedure for the removal of dyes..$^{12}$ Activated carbon, as one of the most 
commonly used adsorbents, could be used to adsorb the organic pigment ${ }^{13-20}$ during the treatment of wastewater, as it has rich pore structure and excellent specific surface area.

At present, however, the main raw material for producing activated carbon is coal, a non-renewable resource, and powdered activated carbon is difficult to separate from the solution after wastewater treatment. Therefore, a growing number of researchers have taken an interest in synthesizing magnetic activated carbon (MAC) 21-24 $^{2}$ or using renewable resources to produce activated carbon. The renewable resources used are mainly industrial and agricultural waste, such as peanut shells, ${ }^{25,26}$ pine nut shells, ${ }^{27}$ banana pseudo-stems and so forth. ${ }^{28}$ Compared with conventional activated carbon, MAC is more applicable in wastewater treatment because it can be easily removed from the solution through magnetic separation technology after adsorbing the pollutants. ${ }^{29}$

Eucalyptus is a renewable resource and grows quickly. Eucalyptus wood sawdust (EWS) could replace coal to produce activated carbon, and if suitable magnetic materials are added, it can become MAC. This does not have the deficiency of being difficult to recycle compared with ordinary powdered activated carbon when applied in wastewater treatment. Although the adsorption behavior of methylene blue (MB) on eucalyptus wood-based activated carbon or magnetic activated carbon is rarely reported, eucalyptus wood-based activated carbon has been used to eliminate cadmium ${ }^{30}$ and chromium(vi ${ }^{31}$ from aqueous solutions.

Herein, eucalyptus wood-based MAC was prepared by singlestep carbonization activation magnetization with $\mathrm{FeCl}_{3}$. $\mathrm{MB}$ was selected as a model dye for the study and the adsorption behavior, adsorption isotherm, kinetics and adsorption mechanism of MB on MAC were comprehensively investigated.

\section{Materials and methods}

\subsection{Materials}

Eucalyptus grandis wood chips, were provided by Guangxi Gaofeng Farm, China. The wood chips were washed to remove dust and any other impurities, dried at $100{ }^{\circ} \mathrm{C}$ for $24 \mathrm{~h}$, then smashed and sieved with 40 and 60 mesh screens, and sawdust with particles of $0.25-0.42 \mathrm{~mm}$ were selected as the precursor for production of activated carbon. Ferric trichloride hexahydrate $\left(\mathrm{FeCl}_{3} \cdot 6 \mathrm{H}_{2} \mathrm{O}\right.$, used as an activator and magnetic agent), methylene blue $\left(\mathrm{C}_{16} \mathrm{H}_{18} \mathrm{~N}_{3} \mathrm{SCl}\right)$, phenol $\left(\mathrm{C}_{6} \mathrm{H}_{5} \mathrm{OH}\right)$, hydrochloric acid $(37 \% \mathrm{HCl})$, iodine $\left(\mathrm{I}_{2}\right)$, potassium iodide $(\mathrm{KI})$, sodium thiosulfate $\left(\mathrm{Na}_{2} \mathrm{~S}_{2} \mathrm{O}_{3}\right)$, potassium dichromate $\left(\mathrm{K}_{2} \mathrm{Cr}_{2} \mathrm{O}_{7}\right)$, copper sulfate pentahydrate $\left(\mathrm{CuSO}_{4} \cdot 5 \mathrm{H}_{2} \mathrm{O}\right)$, sodium phosphate dibasic $\left(\mathrm{NaH}_{2} \mathrm{PO}_{4}\right)$, potassium dihydrogen phosphate $\left(\mathrm{KH}_{2} \mathrm{PO}\right)$, and the other necessary reagents were purchased from the Shanghai Sinopharm Chemical Reagent Company Ltd. (Shanghai, China). All chemicals were of analytical grade and produced in China.

\subsection{Methods}

2.2.1 Single-step method for the preparation for MAC. The MAC was prepared through a one-step carbonization and activation method. Eucalyptus sawdust $(20.0 \mathrm{~g})$ with particles of
0.25-0.42 $\mathrm{mm}$ was mixed with $50 \mathrm{~mL}$ of $\mathrm{FeCl}_{3}$ aqueous solution (the mass ratio of $\mathrm{FeCl}_{3}$ to eucalyptus sawdust was $2: 1,66.6 \mathrm{~g}$ of $\mathrm{FeCl}_{3} \cdot 6 \mathrm{H}_{2} \mathrm{O}$ was dissolved in $50 \mathrm{~mL}$ of distilled water and $\mathrm{FeCl}_{3}$ aqueous solution was obtained) and kept at room temperature for $24 \mathrm{~h}$. Then, the samples were dried, after that the commixture materials were placed into a porcelain crucible and heated for $75 \mathrm{~min}$ in a muffle furnace at $700{ }^{\circ} \mathrm{C}$, the carbonized, activated materials were washed with $\mathrm{HCl}$ aqueous solution, hot and cold deionized water until the $\mathrm{pH}$ of the washing solution reached 6-7, filtered and finally dried at $110{ }^{\circ} \mathrm{C}$ for $24 \mathrm{~h}$. After being smashed and screened through a 120 mesh sieve, the MAC was obtained, weighed, and stored in tightly closed bottles until further analysis.

The yield of the MAC was calculated according to eqn (1).

$$
Y(\%)=M_{\mathrm{AC}} / M_{0} \times 100
$$

In which $M_{\mathrm{AC}}$ is the weight of the prepared MAC sample and $M_{0}$ is the weight of the dried eucalyptus sawdust.

2.2.2 Characterization of the prepared MAC. The adsorption capacity of iodine, methylene blue, phenol and the iron content of the prepared MAC were determined according to the test methods for wooden activated carbon described in the National Standard of China, ${ }^{31-34}$ GB/T 12496.8-2015, GB/T 12496.10-1999, GB/T 12496.12-1999 and GB/T 12496.19-2015, respectively.

The pore volume and specific surface area of the prepared MAC sample was determined according to the test methods for granular activated carbon from coal described in the National Standard of China GB/T 7002.20-2008. Prior to testing, the activated carbon was dried at $150 \pm 5{ }^{\circ} \mathrm{C}$ for $2 \mathrm{~h}$. The porous structural properties of the prepared MAC sample were studied using a $\mathrm{N}_{2}$ adsorption-desorption isotherm measured using a Micromeritics TriStar-3020 at $77 \mathrm{~K}$. The specific surface area was analyzed using the Brunauer-Emmett-Teller (BET) equation at a relative pressure of $P / P_{0}=0.05-0.35$. The micropore volumes $\left(V_{\text {micro }}\right)$ were calculated from the adsorption quantity corresponding to the starting point of the hysteresis ring on the $\mathrm{N}_{2}$ adsorption-desorption isotherm. The mesopore volumes $\left(V_{\text {meso }}\right)$ were calculated using the adsorption quantity corresponding to the terminal point of the hysteresis ring by subtracting the adsorption quantity corresponding to the starting point of the hysteresis ring on the $\mathrm{N}_{2}$ adsorption-desorption isotherm..$^{35}$ The Barrett-Joyner-Halenda (BJH) method was used to obtain the total pore volume and the pore size distribution of the prepared MAC sample. The surface functional group of EWS and the prepared MAC sample was measured using Fourier transform infrared spectrometry (FTIR) (Nicolet 6700, America Nicolet Corporation), and data analysis employing OMNIC software. The crystalline structural information was analyzed using X-ray diffractometry (XRD, UItima IV), within a $2 \theta$ range of $5-80^{\circ}$. The magnetic properties of the prepared MAC were measured on a vibrating sample magnetometer (VSM) (Lake Shore 7410) at room temperature. The magnetic hysteresis curve was plotted and used to analyze the specific saturation magnetization $\left(M_{\mathrm{S}}\right)$, coercivity $\left(H_{\mathrm{c}}\right)$ and residual magnetism $\left(M_{\mathrm{r}}\right)$. The surface appearance and the pores of the prepared 
MAC sample were analyzed using a field emission scanning electron microscope (FESEM) (SUPRA 55 Sapphire) or a field emission transmission electron microscope (FETEM) (JEOL JEM 2100).

\subsubsection{Adsorption behavior of $\mathrm{MB}$ on the prepared MAC}

2.2.3.1 Adsorption isotherms. A batch experiment was conducted to evaluate the adsorption behavior of MB onto the prepared MAC. The adsorption experiments were carried out using $50.0 \mathrm{~mL}$ of $\mathrm{MB}$ solutions with different initial concentrations (50.0-500.0 $\mathrm{mg} \mathrm{\textrm {L } ^ { - 1 }}$, concentration gradient of $50.0 \mathrm{mg} \mathrm{L} \mathrm{L}^{-1}$ ) with $50.0 \mathrm{mg}$ of the activated carbon at various time intervals (from $0 \mathrm{~min}$ to $24 \mathrm{~h}$ ) and temperatures $(25,35,45$, and $55{ }^{\circ} \mathrm{C}$ ) in order to determine the adsorption equilibrium time and the maximum adsorption of $\mathrm{MB}$.

In a typical run, $50.0 \mathrm{~mL}$ of methylene blue $(\mathrm{MB})$ aqueous solution with an initial concentration of $250.0 \mathrm{mg} \mathrm{L}^{-1}$ was placed in a $250 \mathrm{~mL}$ Erlenmeyer flask. $0.0500 \mathrm{~g}$ of the prepared MAC, which was less than $75 \mu \mathrm{m}$ in diameter, was added to the flask, then the flask was put into a digital water-bathing constant temperature vibrator and shaken at a speed of $100 \mathrm{rpm}$ at $308 \mathrm{~K}$ for $24 \mathrm{~h}$ to reach equilibrium. Then, the MAC was separated from the liquid phase methylene blue aqueous solution using magnets and the mixtures were filtered, the filtrate concentration of each solution was determined from the absorbance of the filtrate measured using a UV/VIS spectrophotometer at $\mathrm{MB}$ maximum adsorption wavelengths of $665 \mathrm{~nm}$. The MB mass concentration, $C_{\mathrm{t}}$ or $C_{\mathrm{e}}$, of the filtrate could be calculated according to the relationship calibration curve between the MB mass concentration and absorbance. The amount $q_{\mathrm{t}}\left(\mathrm{mg} \mathrm{g}^{-1}\right)$ of MB adsorbed onto the MAC was determined by the difference between the initial and remaining concentration of the MB solution, calculated using eqn (2):

$$
q_{\mathrm{t}(\mathrm{e})}=\frac{\left(C_{0}-C_{\mathrm{t}(\mathrm{e})}\right) V}{1000 \times M_{\mathrm{AC}}}
$$

In which $C_{0}, C_{\mathrm{t}}$ and $C_{\mathrm{e}}$ were the initial, remaining and equilibrium concentration $\left(\mathrm{mg} \mathrm{L}^{-1}\right)$ of the MB solution, respectively, $V$ was the volume of the $\mathrm{MB}$ aqueous solution $(\mathrm{mL})$, and $M_{\mathrm{AC}}$ was the mass of the added MAC $(\mathrm{g})$.

Prior to all of above described processes, the relationship calibration curve between the MB mass concentration and the absorbance was established according to the Lambert-Beer law. The method of fitting the standard curve was as follows: firstly, the maximum absorption wavelength of the MB aqueous solution in the visible region was determined (665 nm); secondly, accurate concentrations of $\mathrm{MB}$ aqueous solution (0.1458, $0.2916,0.729,1.458$ and $2.916 \mathrm{mg} \mathrm{L}^{-1}$ respectively) were prepared and the absorbance at a maximum wavelength of $665 \mathrm{~nm}$ was determined; finally, the relationship calibration standard curve between the absorbance and concentration of the MB aqueous solution was plotted.

When the adsorption process reached an equilibrium state, the distribution of the adsorbate MB molecules between the liquid phase $\mathrm{MB}$ aqueous solution and the solid phase of the prepared MAC was analyzed using the adsorption isotherm, ${ }^{36}$ and Langmuir, ${ }^{37}$ Freundlich, ${ }^{38}$ Temkin, ${ }^{39}$ and DubininRadushkevich $^{\mathbf{4 0}}$ isotherm model equations were used to fit the experimental data for $\mathrm{MB}$ adsorption on the prepared MAC. These isotherm model equations can be expressed as eqn (3)(10).

Langmuir isotherm:

$$
\begin{array}{r}
\frac{c_{\mathrm{e}}}{q_{\mathrm{e}}}=\frac{1}{k_{\mathrm{L}} q_{\mathrm{m}}}+\frac{c_{\mathrm{e}}}{q_{\mathrm{m}}} \\
k_{\mathrm{L}}=k_{0} \exp \left(-E_{\mathrm{a}} / R T\right) \\
R_{\mathrm{L}}=1 /\left(1+k_{\mathrm{L}} C_{\mathrm{e}}\right)
\end{array}
$$

Freundlich isotherm:

$$
\ln q_{\mathrm{e}}=\frac{1}{n} \ln c_{\mathrm{e}}+\ln k_{\mathrm{F}}
$$

Temkin isotherm:

$$
q_{\mathrm{e}}=\frac{R T}{b_{\mathrm{T}}} \ln A_{\mathrm{T}}+\frac{R T}{b_{\mathrm{T}}} \ln c_{\mathrm{e}}
$$

Dubinin-Radushkevich isotherm:

$$
\begin{gathered}
\ln q_{\mathrm{e}}=\ln q_{\mathrm{s}}-k_{\mathrm{ad}} \varepsilon^{2} \\
\varepsilon=R T \ln \left[1+\frac{1}{C_{\mathrm{e}}}\right] \\
E=\frac{1}{\sqrt{2 k_{\mathrm{ad}}}}
\end{gathered}
$$

In which $q_{\mathrm{e}}\left(\mathrm{mg} \mathrm{g}^{-1}\right)$ was the amount of $\mathrm{MB}$ adsorbed at equilibrium, $c_{\mathrm{e}}\left(\mathrm{mg} \mathrm{L}^{-1}\right)$ was the equilibrium concentration of the MB solution; $q_{\mathrm{m}}\left(\mathrm{mg} \mathrm{g}^{-1}\right)$ and $q_{\mathrm{s}}\left(\mathrm{mg} \mathrm{g}^{-1}\right)$ were the maximum amount of $\mathrm{MB}$ adsorption in the Langmuir isotherm and the Dubinin-Radushkevich isotherm model, respectively; $k_{\mathrm{L}}(\mathrm{L}$ $\mathrm{mg}^{-1}$ ) was the Langmuir adsorption equilibrium constant related to the adsorption rate. The $E_{\text {a }}$ (activation energy) can be calculated using $k_{\mathrm{L}}$ at different temperatures and the adsorption process can be determined whether there is a chemical process $\left(E_{\mathrm{a}}>0\right)$ or a physical process $\left(E_{\mathrm{a}} \leq 0\right)$ in the Langmuir isotherm. The $R_{\mathrm{L}}$ value indicates the nature of adsorption to be either unfavorable $\left(R_{\mathrm{L}}>1\right)$, linear $\left(R_{\mathrm{L}}=1\right)$, favorable $\left(0<R_{\mathrm{L}}<1\right)$ or irreversible $\left(R_{\mathrm{L}}=0\right) . k_{\mathrm{F}}\left(\left(\mathrm{mg} \mathrm{g}^{-1}\right)\left(\mathrm{L} \mathrm{mg}^{-1}\right)^{1 / n}\right)$ is the Freundlich constant representing the adsorption capacity, $n$ was the Freundlich constant depicting the adsorption intensity; $R$ and $T$

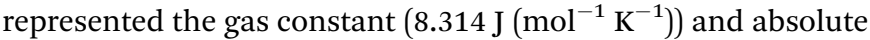
temperature $(\mathrm{K})$, respectively; $b_{\mathrm{T}}$ is the constant related to the adsorption heat and $A_{\mathrm{T}}$ is the Temkin isotherm constant; $k_{\mathrm{ad}}$ $\left(\mathrm{mol}^{2} \mathrm{~kJ}^{-2}\right)$ is the constant of the adsorption energy, which is related to the mean adsorption energy in the DubininRadushkevich isotherm model; $E$ is the mean adsorption energy, for which the value can determine whether a physisorption process or chemisorption process occurred in the Dubinin-Radushkevich isotherm, as physisorption processes have adsorption energies in the range of 1-8 $\mathrm{kJ} \mathrm{mol}^{-1}$ and chemisorption processes have an adsorption energy larger than $8 \mathrm{~kJ} \mathrm{~mol}{ }^{-1}{ }^{41}$ 
2.2.3.2 Adsorption thermodynamics. The thermodynamic behavior of MB adsorption onto MAC was evaluated using the thermodynamic parameters including the change in the Gibbs free energy $(G)$, enthalpy $(H)$, and entropy $(S)$. The change in the Gibbs free energy $(\Delta G)$ can be used as a standard of judgment for whether an adsorption process is spontaneous, the change of enthalpy $(\Delta H)$ describes whether an adsorption process is an exothermic process and the change of the entropy $(\Delta S)$ indicates whether the molecular movements have become more unordered. These parameters are calculated from the following eqn (11)-(14):

$$
\begin{gathered}
\ln K_{\mathrm{d}}=-\frac{\Delta H}{R T}+\frac{\Delta S}{R} \\
K_{\mathrm{d}}=\frac{q_{\mathrm{e}}}{c_{\mathrm{e}}} \\
\Delta G=-R T \ln \left(K_{\mathrm{d}}\right) \\
\Delta G=\Delta H-T \Delta S
\end{gathered}
$$

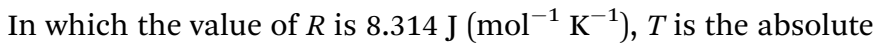
temperature $(\mathrm{K})$, and $K_{\mathrm{d}}$ is the distribution coefficient for the adsorption at temperature $T$.

2.2.3.3 Adsorption kinetics. The kinetic experiments were carried out with $50 \mathrm{~mL}$ of MB solutions with initial concentrations of 150 or $250 \mathrm{mg} \mathrm{L}^{-1}$ with $50 \mathrm{mg}$ of the MAC in $250 \mathrm{~mL}$ Erlenmeyer flasks. The flasks were put in a digital water-bathing constant temperature vibrator and shaken at a speed of $100 \mathrm{rpm}$ at temperatures of 298, 308, 318 and $328 \mathrm{~K}$ for different periods of time, respectively. Then the MAC was separated from the liquid phase MB aqueous solution using magnets, the mixtures were filtered, the filtrate was analyzed to determine the MB dye concentration, and the amount $q_{\mathrm{t}}\left(\mathrm{mg} \mathrm{g}^{-1}\right)$ of $\mathrm{MB}$ adsorbed onto MAC was calculated according to eqn (2). The adsorption kinetics of the MB were investigated using the pseudo-firstorder rate equation, the pseudo-second-order rate equation and the intraparticle diffusion model rate equation. The three sorption kinetic equations are expressing as follows in eqn (15)(17):

Pseudo-first-order equation:

$$
\ln \left(q_{\mathrm{e}}-q_{\mathrm{t}}\right)=\ln q_{\mathrm{e}}-k_{1} t
$$

Pseudo-second-order equation:

$$
\frac{t}{q_{\mathrm{t}}}=\frac{1}{k_{2} q_{\mathrm{e}}{ }^{2}}+\frac{1}{q_{\mathrm{e}}} t
$$

Intraparticle diffusion equation:

$$
q_{\mathrm{t}}=k_{3} t^{1 / 2}+C
$$

In which $q_{\mathrm{e}}$ and $q_{\mathrm{t}}$ were the amounts of MB adsorbed $\left(\mathrm{mg} \mathrm{g}^{-1}\right)$ at the equilibrium time and at time $t(\mathrm{~min})$, respectively; $k_{1}$ $\left(\mathrm{min}^{-1}\right)$ was the rate constant of the pseudo-first-order equation and $k_{2}\left(\mathrm{~g} \mathrm{mg}^{-1} \mathrm{~min}\right)$ was the rate constant of the pseudo-secondorder equation, $k_{3}\left(\mathrm{mg} g \mathrm{~min}^{1 / 2}\right)$ was the intraparticle diffusion rate constant, $C\left(\mathrm{mg} \mathrm{g}^{-1}\right)$ was a constant associated with the thickness of the boundary layer, for which a higher value corresponded to a greater effect on the limiting boundary layer and a greater contribution of the surface sorption in the rate controlling step. The $t$ is the time of absorption.

2.2.3.4 Adsorption mechanism of $M B$ on the prepared MAC. Fourier transform infrared spectrometry, transmission electron microscopy (TEM) and X-ray photoelectron spectroscopy (XPS) analysis of the prepared MAC before and after MB adsorption were used to determine the adsorption mechanism of $\mathrm{MB}$ on the prepared MAC.

\section{Results and discussion}

The iodine number, $\mathrm{MB}$ adsorption and phenol adsorption of the prepared eucalyptus wood-based MAC were determined using the test methods for wooden activated carbon described in the National Standard of China and were found to be 473.14, 228.22 and $70.90 \mathrm{mg} \mathrm{g}^{-1}$, respectively. The MB adsorption of the prepared MAC in this study was higher than that reported by Bedin et al., ${ }^{42} 211.3 \mathrm{mg} \mathrm{g}^{-1}$ of $\mathrm{MB}$ was adsorbed onto the spherical activated carbon, which was estimated using the Langmuir isotherm models. The adsorption capacity was higher than the adsorption of $143.53 \mathrm{mg} \mathrm{g}^{-1}$ of MB on mesoporousactivated carbon prepared from chitosan flakes as reported by F. Marrakchi, et al. ${ }^{5}$ However, the MB adsorption was lower than the mesoporous activated carbon from rattan furniture waste carbonized using hydrothermal carbonization and activated by $\mathrm{NaOH}$ with a maximum MB uptake of $359 \mathrm{mg} \mathrm{g}^{-1},{ }^{43}$ the possible cause for this could be because the pores of the carbon were blocked by the magnetic material.

\subsection{Characterization of the prepared MAC}

3.1.1 Pore characterization of the prepared MAC. The pore structure characterization of the adsorbents was determined from the adsorption of inert gases. ${ }^{44}$ The adsorption-desorption isotherms of $\mathrm{N}_{2}$ at $77 \mathrm{~K}$ and the BJH pore size distribution of the MAC prepared from eucalyptus wood sawdust activated using $\mathrm{FeCl}_{3}$ are shown in Fig. 1. The properties and parameters of the pores, including the $S_{\mathrm{BET}}, V_{\text {mic }}, V_{\text {mes }}, V_{\text {total }}$, mesoporosity and $W_{\mathrm{d}}$ are listed in Table 1.

The prepared MAC was a microporous and mesoporous carbon material. According to the IUPAC classification, the isotherms of the MAC were typical Type IV adsorption isotherms. The MAC derived from eucalyptus sawdust activated with $\mathrm{FeCl}_{3}$ had the characteristics of a mesoporous material, as obvious hysteresis loops can be seen in the adsorptiondesorption isotherms, this was also proved by the mesoporosity of $36 \%$ and the average diameter of $2.71 \mathrm{~nm}$, as shown in Table 1. This statement was also confirmed by the pore size distribution of MAC shown in Fig. 1 analyzed using the BJH theory.

The BET surface area of the prepared MAC calculated using the standard BET method was $645.23 \mathrm{~m}^{2} \mathrm{~g}^{-1}$. The total pore volume of the prepared MAC was $0.44 \mathrm{~cm}^{3} \mathrm{~g}^{-1}$. The size of the formed pores influences the porosity, the total surface area available for adsorption and most importantly, the size of the 

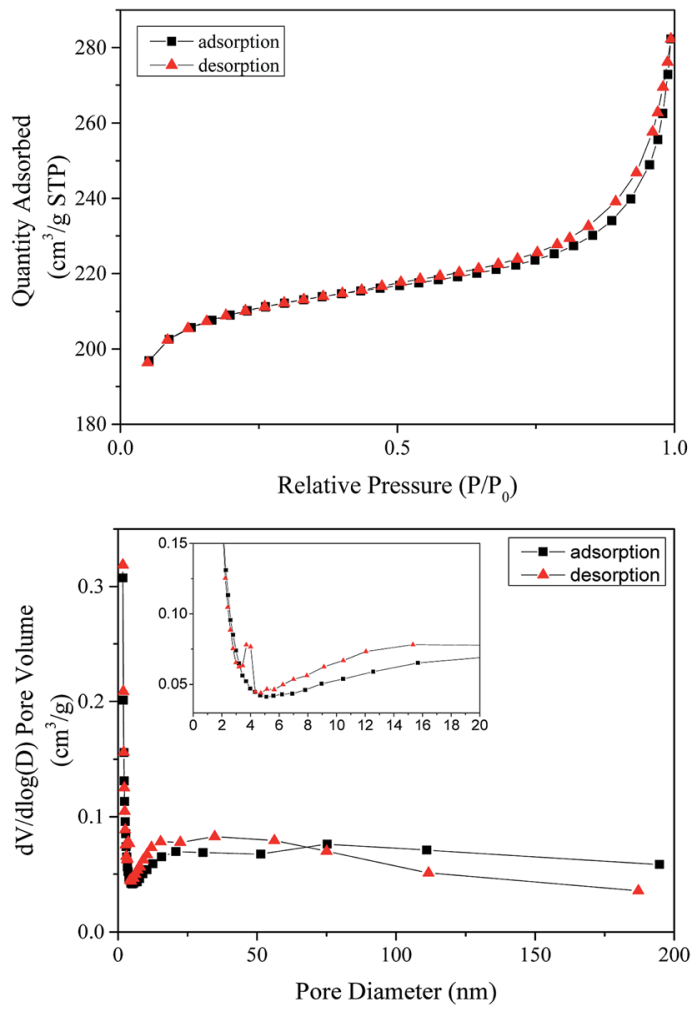

Fig. $1 \mathrm{~N}_{2}$ adsorption-desorption isotherms at $77 \mathrm{~K}$ and the $\mathrm{BJH}$ pore size distribution of the prepared MAC.

molecules that can diffuse into the solid. ${ }^{45}$ The average pore diameter of the prepared MAC was $2.71 \mathrm{~nm}$, greater than the MB molecular diameter of $0.8 \mathrm{~nm}$ (MB molecule width of $1.43 \mathrm{~nm}$, depth of $0.61 \mathrm{~nm}$, thickness of $0.4 \mathrm{~nm},{ }^{46}$ and a molar volume of $241.9 \mathrm{~cm}^{3} \mathrm{~mol}^{-1}$ (ref. 46)), which is of benefit for the MB molecule to enter the pores of MAC and promotes contact between the adsorption sites of MAC and the MB molecules, improving the $\mathrm{MB}$ adsorption on the surface of the prepared MAC.

3.1.2 Magnetic properties. The magnetic properties of the MAC were evaluated using the magnetic hysteresis curves obtained, these are the most important characteristics of a magnetic material, and reflect magnetic indicators including the coercive force $\left(H_{\mathrm{c}}\right)$, saturation magnetization $\left(M_{\mathrm{s}}\right)$ and remnant magnetization $\left(M_{\mathrm{r}}\right)$, the results are displayed in Fig. 2. Specific magnetic parameters of the prepared MAC are also compiled in Table 2.

The results, magnetization hysteresis loops and the saturation magnetization of $30.37 \mathrm{emu} \mathrm{g}^{-1}$ indicated that the activated carbon was successfully coated with the magnetic

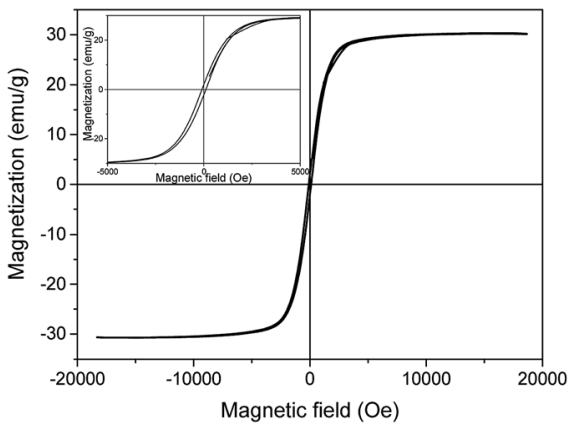

Fig. 2 Magnetic hysteresis loops of the prepared MAC

material. Similar results were reported by Song et al., ${ }^{47}$ who synthesized MAC via a modified coprecipitation reaction and the value of the saturation magnetization of the MAC was $33.207-37.535 \mathrm{emu}^{-1}$. The coercive force is one of the main properties that can be used to distinguish soft magnetic materials from hard magnetic materials. In generally, soft magnetic materials are materials that have a coercive force from $0.16 \mathrm{~A}$ $\mathrm{m}^{-1}(0.002 \mathrm{Oe})$ to $400 \mathrm{~A} \mathrm{~m}^{-1}$ (5 Oe), and hard magnetic materials have a coercive force from $10 \mathrm{kA} \mathrm{m}^{-1}(125 \mathrm{Oe})$ to $1 \mathrm{MA} \mathrm{m}^{-1}$ (12 kOe). ${ }^{48}$ The coercive force of the prepared MAC in this study was $108.51 \mathrm{Oe}$, meaning it is a hard magnetic material. Moreover, the results showed that the remnant magnetization $\left(M_{\mathrm{r}}\right)$ was small and the number was $2.46 \mathrm{emu} \mathrm{g}^{-1}$. All in all, the prepared activated carbon was magnetic, and could be separated using a magnetic separator. This meant that the prepared activated carbon could be recycled from waste water via a simple magnetic separator, meaning that the MAC could be separated and avoiding secondary pollution.

3.1.3 FTIR of the EWS and MAC. The FTIR spectrum of the raw materials of EWS and the prepared MAC is shown in Fig. 3. The peak at $3000-3500 \mathrm{~cm}^{-1}$ was assigned to the hydroxyl $-\mathrm{OH}$. The peaks at $1799 \mathrm{~cm}^{-1}$ were identified as the $\mathrm{C}=\mathrm{O}$ stretching vibration from the carbonyl and carboxyl groups. ${ }^{32}$ The peak at $1579 \mathrm{~cm}^{-1}$ was regarded as being from the $\mathrm{C}=\mathrm{C}$ stretching vibration. ${ }^{49}$ The sharp peak that appeared at $1400 \mathrm{~cm}^{-1}$ may belong to the bending vibrations of the $\mathrm{C}-\mathrm{N}$ group $^{50}$ or the stretching vibration of the $\mathrm{COO}$ group in the carboxylic groups. ${ }^{51}$ The characteristic peak at $1122 \mathrm{~cm}^{-1}$ was attributed to the $\mathrm{C}-\mathrm{O}$ stretching vibrations. ${ }^{52}$ The peaks at 622 and $588 \mathrm{~cm}^{-1}$ were ascribed to the $\mathrm{Fe}-\mathrm{O}$ bending vibrations of $\mathrm{Fe}_{3} \mathrm{O}_{4}$ or $\gamma$ $\mathrm{Fe}_{2} \mathrm{O}_{3} \cdot{ }^{53-56}$ The peak at $877 \mathrm{~cm}^{-1}$ was assigned to the $\mathrm{Fe}-\mathrm{O}$ bending vibrations..$^{55}$ The peak at $696 \mathrm{~cm}^{-1}$ could also be caused by the $\mathrm{Fe}-\mathrm{O}$ bond vibration. ${ }^{57}$ Compared with the FTIR spectrum of the raw material of EWS, a peak for Fe-O appeared and the $-\mathrm{CH}_{3}$ peak disappeared in the FTIR spectrum of the

Table 1 The pore parameters of the prepared MAC

\begin{tabular}{llllll}
\hline$S_{\text {BET }}\left(\mathrm{m}^{2} \mathrm{~g}^{-1}\right)$ & $V_{\text {total }}\left(\mathrm{cm}^{3} \mathrm{~g}^{-1}\right)$ & $V_{\text {micro }}\left(\mathrm{cm}^{3} \mathrm{~g}^{-1}\right)$ & $V_{\text {mesopore }}\left(\mathrm{cm}^{3} \mathrm{~g}^{-1}\right)$ & $\begin{array}{l}\text { Mesoporosity } \\
(\%)\end{array}$ & $W_{\mathrm{d}}(\mathrm{nm})$ \\
\hline 645.23 & 0.44 & 0.28 & 0.16 & 36 & 2.71
\end{tabular}


Table 2 Magnetic properties of MAC

\begin{tabular}{lllll}
\hline Materials & $H_{\mathrm{c}}(\mathrm{Oe})$ & $M_{\mathrm{s}}\left(\mathrm{emu} \mathrm{g}^{-1}\right)$ & $M_{\mathrm{r}}\left(\mathrm{emu} \mathrm{g}^{-1}\right)$ & $M_{\mathrm{r}} / M_{\mathrm{s}}$ \\
\hline MAC & 108.51 & 30.37 & 2.46 & 0.081
\end{tabular}

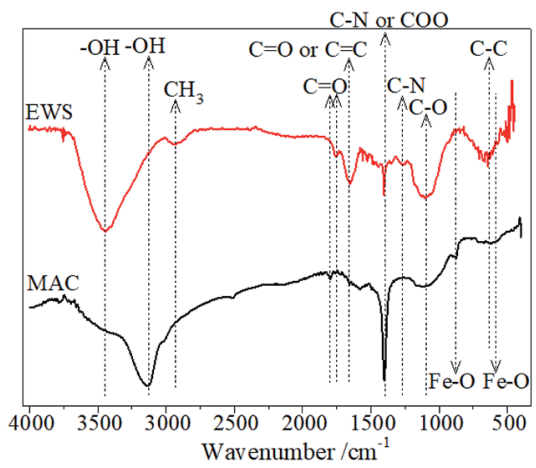

Fig. 3 FTIR spectrum of the EWS and MAC.

prepared MAC. These characteristic adsorption peaks showed that some iron oxides were doped into the prepared carbon material.

3.1.4 XRD of the EWS and MAC. The XRD spectrum of the raw material of EWS and the prepared MAC is shown in Fig. 4. The peaks at $2 \theta-16.60^{\circ}, 18.30^{\circ}, 22.21^{\circ}, 34.68^{\circ}$ in the XRD spectrum of EWS represent the major crystal planes of (101), (10-1), (002) and (040) for cellulose in the eucalyptus sawdust, respectively. ${ }^{58}$ The characteristic peak of cellulose in EWS disappeared, indicating that the EWS had undergone pyrolysis, its structure was broken, and carbon was formed. The peaks at $2 \theta-30.10^{\circ}, 35.45^{\circ}, 43.12^{\circ}, 53.57^{\circ}, 56.92^{\circ}$, and $62.56^{\circ}$ on the XRD spectrum for MAC, are indexed as the planes of (220), (311), (400), (422), (511) and (400) $)^{59}$ and are characteristic absorption peaks for magnetite $\left(\mathrm{Fe}_{3} \mathrm{O}_{4}\right)$ according to PDF card 19-0629. The XRD spectrum showed that the magnetic carbon was successfully synthesized and the magnetic material was $\mathrm{Fe}_{3} \mathrm{O}_{4} \cdot{ }^{59}$ The characteristic peaks for the activated carbon were

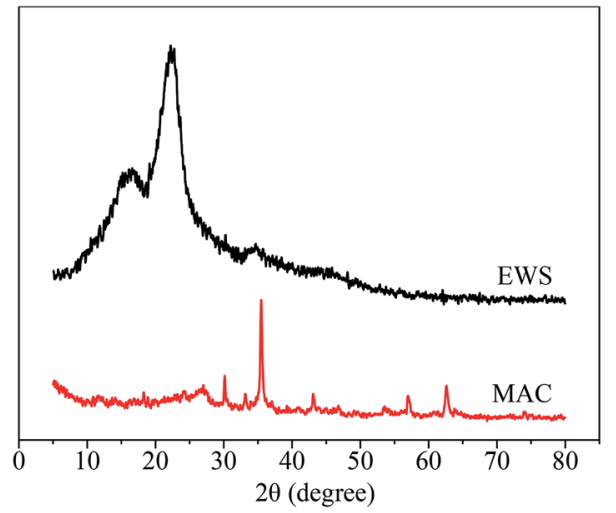

Fig. 4 XRD spectrum of EWS and MAC. not obvious, and this phenomenon could be due to the influence of $\mathrm{Fe}_{3} \mathrm{O}_{4}$ with a high absorption peak and a high crystallinity. ${ }^{60}$

3.1.5 SEM of the prepared MAC. The surface topography of the prepared MAC was investigated using scanning electron microscopy (SEM). Fig. 5 shows the SEM images of the carbon materials at different factors of magnification. Some columnar channels can be seen in Fig. 5a (magnified 2000 times) and Fig. 5b (magnified 5000 times), which may come from wood fiber present in the eucalyptus sawdust. Some slit-shaped channels and tiny channels in addition to the columnar channels were found, and may be formed by activation of $\mathrm{FeCl}_{3}$ during the carbonization activation process. Of course, parts of the tiny channels were dilapidated and became layerlike and porous in structure, as shown in Fig. 5c (magnified 5000 times) and Fig. 5d (magnified 20000 times). The magnetic materials were half embedded in the interior or surface of a hole, and are shown in Fig. 5b (magnified 5000 times), Fig. 5e (magnified 20000 times) and Fig. $5 \mathrm{f}$ (magnified 50000 times). Some of the $\mathrm{Fe}_{3} \mathrm{O}_{4}$ present aggregated into large particles as shown in Fig. $5 f$.

\subsection{Adsorption behavior of MB on the prepared MAC}

3.2.1 Adsorption isotherms. The standard calibration curve of MB, mass concentration and absorbance have been plotted at the maximum wavelength of $665 \mathrm{~nm}$, and the linear equation plotted between the MB mass concentration and absorbance was $A=0.00785+0.20577 C$ ( $C$ was in the range of $\left.0.1458-2.9160 \mathrm{mg} \mathrm{L}^{-1}\right)$, in which $A$ is the absorbance, $C$ is the mass concentration of $\mathrm{MB}$, and $R$ is the correlation
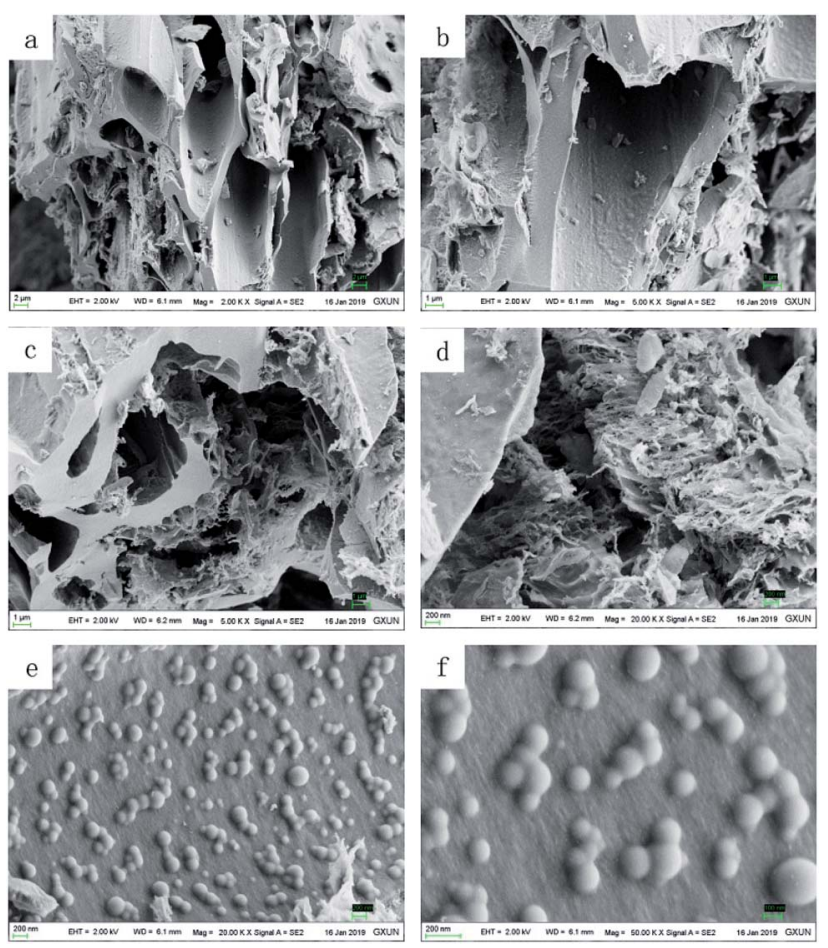

Fig. 5 SEM images of the prepared MAC. 
coefficient. The value of $R^{2}$ was 0.9995 , which manifested a good correlation between the MB mass concentration and absorbance.

The adsorption isotherms described the distribution of adsorbate molecules between the liquid phase and the solid phase when the system reached an equilibrium; and the fitting of the isotherm data to different adsorption isotherm models was important in order to find a sustainable model that described the adsorption process.

The isotherm data of the MB adsorption on the prepared MAC were fitted to four adsorption isotherm models, namely the Langmuir, Freundlich, Temkin and Dubinin-Radushkevich isotherm models in their linear forms. Fig. 6 shows the fitted isotherm. The specific fitting isotherm parameters for the
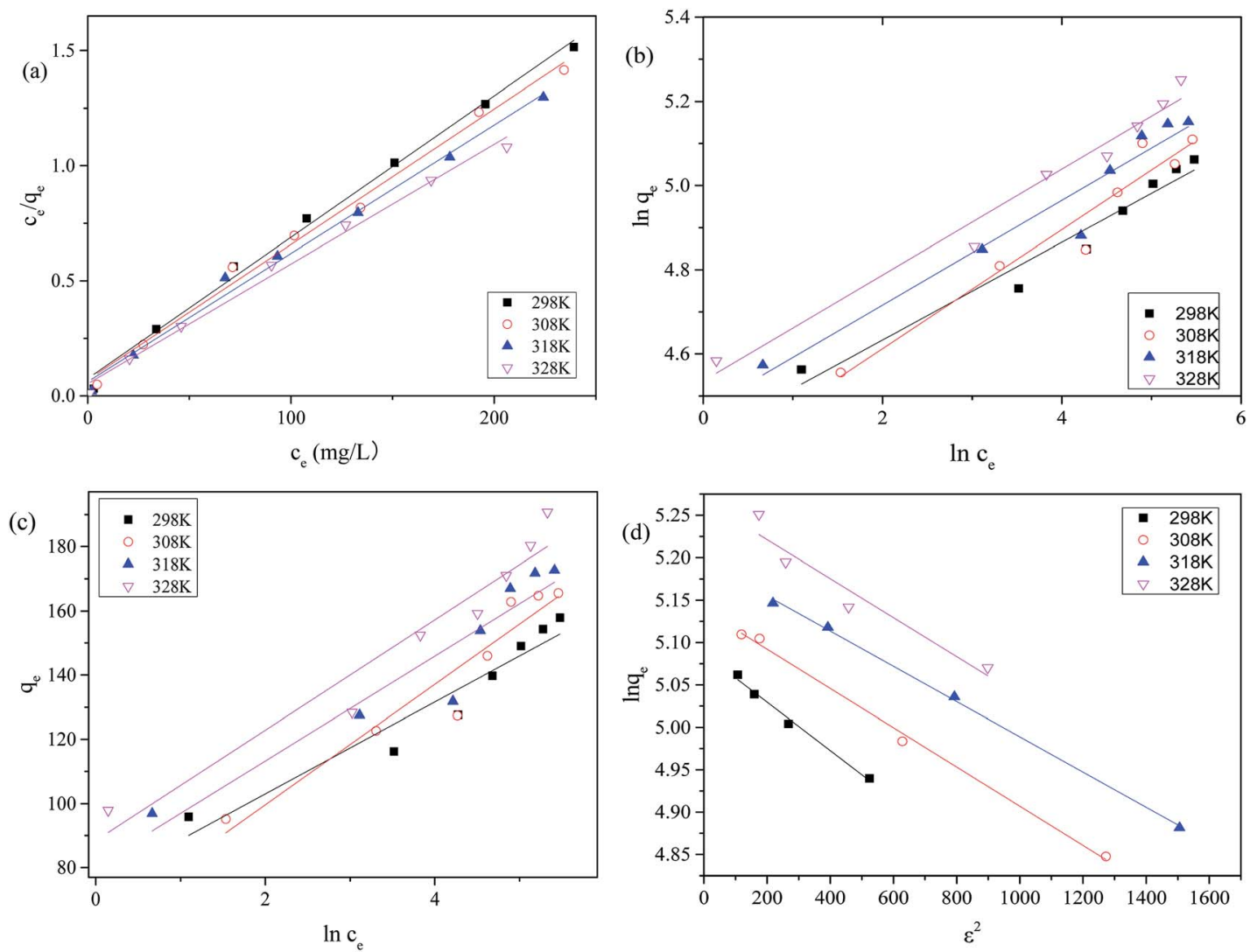

Fig. 6 (a) Langmuir; (b) Freundlich; (c) Temkin isotherm; and (d) Dubinin-Radushkevich isotherm models of MB adsorption on MAC.

Table 3 The adsorption isotherm parameters of MB on the prepared MAC

\begin{tabular}{|c|c|c|c|c|c|c|c|c|c|}
\hline \multirow[b]{2}{*}{$T(\mathrm{~K})$} & \multicolumn{5}{|l|}{ Langmuir } & \multicolumn{4}{|c|}{ Freundlich } \\
\hline & $q_{\max }\left(\mathrm{mg} \mathrm{g}^{-1}\right)$ & $K_{\mathrm{L}}\left(\mathrm{L} \mathrm{mg}^{-1}\right)$ & $R_{\mathrm{L}}$ & $E_{\mathrm{a}}\left(\mathrm{kJ} \mathrm{mol}^{-1}\right)$ & $R^{2}$ & $K_{\mathrm{F}}(\mathrm{mg}$ & $\left.\mathrm{ng}^{-1}\right)^{1 / n}$ & $n$ & $R^{2}$ \\
\hline 308 & 169.78 & 85.18 & $0.080-0.717$ & & 0.9904 & 75.90 & & 7.07 & 0.9290 \\
\hline 318 & 179.21 & 91.46 & $0.076-0.849$ & & 0.9907 & 87.12 & & 8.04 & 0.9297 \\
\hline \multirow[t]{2}{*}{328} & 192.31 & 99.48 & $0.073-0.900$ & & 0.9912 & 90.28 & & 7.94 & 0.9702 \\
\hline & \multicolumn{3}{|l|}{ Temkin } & \multicolumn{6}{|c|}{ Dubinin-Radushkevich } \\
\hline$T(\mathrm{~K})$ & $b_{\mathrm{T}}$ & $A_{\mathrm{T}}$ & $R^{2}$ & $q_{\mathrm{s}}\left(\mathrm{mg} \mathrm{g}^{-1}\right)$ & \multicolumn{2}{|c|}{$k_{\mathrm{ad}}\left(\mathrm{mol}^{2} \mathrm{~kJ}^{-2}\right)$} & $R^{2}$ & \multicolumn{2}{|c|}{$E\left(\mathrm{~kJ} \mathrm{~mol}^{-1}\right)$} \\
\hline 298 & 172.99 & 179.85 & 0.9117 & 161.85 & \multirow{2}{*}{\multicolumn{2}{|c|}{$2.31 \times 10^{-4}$}} & 0.9852 & \multicolumn{2}{|c|}{41.87} \\
\hline 308 & 136.42 & 27.28 & 0.9031 & 170.44 & & & 0.9951 & \multicolumn{2}{|c|}{46.48} \\
\hline 318 & 161.90 & 139.10 & 0.8872 & 180.67 & \multicolumn{2}{|c|}{$2.08 \times 10^{-4}$} & 0.9982 & \multicolumn{2}{|c|}{49.05} \\
\hline
\end{tabular}


adsorption of MB on the prepared MAC are shown in Table 3. Table 3 shows that the experimental data preferentially fits the Langmuir isotherm, the fitted Langmuir isotherm model gave the best correlation coefficient $(R)$ with $R^{2}$ values of 0.9941 , $0.9904,0.9907$ and 0.9912 at 298, 308, 318 and $328 \mathrm{~K}$, respectively, compared with the Freundlich, Temkin and DubininRadushkevich isotherm models, which demonstrates that the adsorption of $\mathrm{MB}$ on the prepared MAC is by monolayer adsorption. The $E_{\mathrm{a}}$, calculated using the $k_{\mathrm{L}}$ at different temperatures was $5.19 \mathrm{~kJ} \mathrm{~mol}^{-1}$ (more than zero) and indicated that the adsorption process of MB on the prepared MAC was by a chemical process. The $R_{\mathrm{L}}$ values of $0.073-0.900$ from the Langmuir isotherm indicate that the nature of adsorption of $\mathrm{MB}$ on the prepared MAC was favorable $\left(0<R_{\mathrm{L}}<1\right)$. As for the Freundlich isotherm model, the Freundlich constant, $n$, depicted the adsorption intensity, the value of $1 / n$ was generally between 0 and 1 , and the magnitude of the $1 / n$ value indicated the extent of the influence of the MB concentration on the adsorption capacity. The smaller the $1 / n$, the better the adsorption. When $1 / n$ was in the range $0.1-0.5$, it was easy to adsorb; when $1 / n$ was more than 2 , it was difficult to adsorb. The Freundlich constant, $n$, of 7.07-8.61, and $1 / n$ of $0.1161-0.1414$, indicated that the adsorption of MB on the prepared MAC was easy. For the equilibrium adsorption data of MB on the adsorbent in an aqueous solution, other researchers ${ }^{61}$ have drawn the same conclusion that the equilibrium adsorption data fitted the Langmuir isotherm better.

Fig. 6 gives the impression that among the Langmuir, Freundlich, Temkin and Dubinin-Radushkevich isotherm models, the Langmuir isotherm model is most suitable for describing the adsorption behavior of MB on the prepared MAC. The maximum MB adsorption capacity of $162.87-192.31 \mathrm{mg} \mathrm{g}^{-1}$ calculated from the fitted Langmuir was less than the reported value of $259.25 \mathrm{mg} \mathrm{g}^{-1,{ }^{62}}$ which was calculated from Sips isotherm fitting and reported by Theydan and Ahmed, ${ }^{62}$ they also compared the maximum MB adsorption capacity to those obtained in other studies concerning activated carbons prepared from various agricultural waste, and concluded that the prepared activated carbon can be classified as one of the most effective adsorbents for the removal of MB from wastewater. According to the report published by Theydan and Ahmed, the MB adsorption value on the eucalyptus wood-based magnetic activated carbon was within the range of effective adsorbents. The maximum MB adsorption value of 162.87$192.31 \mathrm{mg} \mathrm{g}^{-1}$ calculated from the Langmuir model was similar to the value of 195.55 reported by Mehrorang et al. ${ }^{63}$ who synthesized $\gamma-\mathrm{Fe}_{2} \mathrm{O}_{3}$ and loaded it onto activated carbon for ultrasonic assisted adsorption of dyes. Therefore the prepared MAC could also be classified as an effective adsorbent and can effectively remove MB from wastewater. The Temkin isotherm model came from an assumption that the free energy of sorption was a function of the surface coverage owing to adsorbate/ adsorbent interactions. ${ }^{64}$ The adsorption behavior of MB on the prepared MAC was not suitable for fitting to a Temkin isotherm model, as the value of $R^{2}$ was too low (in the range of $0.8872-$ 0.9283). The Dubinin-Radushkevich isotherm model is a common model, and the value of the free energy, which reveals adsorption mechanism information about the adsorption process, can be calculated according the slope of the line of the Dubinin-Radushkevich equation. The related line equations are shown as eqn (8)-(10). For the $E$ value, the apparent free energies, values between 1 and $8 \mathrm{~kJ} \mathrm{~mol}^{-1}$ correspond to the physisorption and an $E$ value of more than $8 \mathrm{~kJ} \mathrm{~mol}^{-1}$ corresponds to chemisorption. ${ }^{41}$ The $E$ values for the DubininRadushkevich isotherm model analysis of MB adsorption on the prepared MAC were $41.87,46.48,49.05$ and $46.65 \mathrm{~kJ} \mathrm{~mol}^{-1}$ at $298,308,318$ and $328 \mathrm{~K}$, respectively. This indicates that the MB adsorption process on the prepared magnetic carbon was a chemisorption process, which was consistent with the analysis results of the Langmuir isotherm model.

The relationship between the equilibrium absorption capacity $\left(q_{\mathrm{e}}\right)$ and the equilibrium MB concentrations $\left(c_{\mathrm{e}}\right)$ is shown in Fig. 7. Fig. 7 exhibited a changing trend, in that the equilibrium absorption capacity $\left(q_{\mathrm{e}}\right)$ increased with the increasing equilibrium MB concentration $\left(c_{\mathrm{e}}\right)$, which meant that the amount of absorption of MB on the prepared MAC increased with an increase in the initial MB concentration. The absorption speed at low $c_{\mathrm{e}}$ was higher than that at high $c_{\mathrm{e}}$, a similar finding was reported by Yang et al. ${ }^{65}$ who also explained that the absorption efficiency with a low initial MB concentration was higher than that observed from a high initial concentration.

3.2.2 Adsorption thermodynamics. The thermodynamic parameters, including the change in the Gibbs free energy $(\Delta G)$, enthalpy $(\Delta H)$, and entropy $(\Delta S)$ were estimated using the eqn (11)-(13) as shown in a preceding section of the paper (2.2.3.2). The results are displayed in Table 4 and Fig. 8. The $\Delta H^{0}$ and $\Delta S^{0}$ can be calculated from the slope and the intercept of the van't Hoff linear plot (negative slope) ${ }^{66}$ of $\ln K_{\mathrm{d}}$ versus $1 / T$, as shown in Fig. 8. The specific thermodynamic parameters for the initial MB concentration of 150 and $250 \mathrm{mg} \mathrm{L}^{-1}$ adsorption on the prepared MAC are shown in Table 4. All of the negative values for the Gibbs free energy $\Delta G^{0}$ suggest that the adsorption of MB on the prepared MAC was spontaneous, and the enhancement of the $\Delta G^{0}$ negative values with an increase in the temperature suggested that the adsorption was more favorable at higher temperatures. ${ }^{41}$ The value of $\Delta H^{0}$ was positive, which implied the adsorption process was endothermic and chemical in

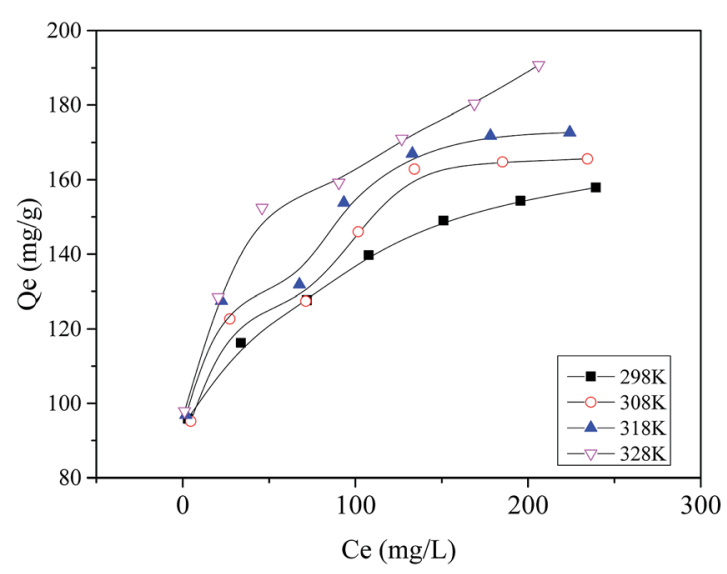

Fig. 7 Adsorption isotherm for MB on the prepared MAC. 
Table 4 Thermodynamics parameters for MB adsorption on the prepared MAC at initial concentrations of $150 \mathrm{mg} \mathrm{L}^{-1}$ and $250 \mathrm{mg} \mathrm{L}^{-1}$

\begin{tabular}{|c|c|c|c|c|c|c|c|c|}
\hline \multirow[b]{2}{*}{$C_{0}\left(\mathrm{mg} \mathrm{L}^{-1}\right)$} & \multirow{2}{*}{$\begin{array}{l}\Delta H^{0}(\mathrm{~kJ} \\
\left.\mathrm{mol}^{-1}\right)\end{array}$} & \multirow{2}{*}{$\begin{array}{l}\Delta S^{0}(\mathrm{~J} \\
\left.\left(\mathrm{mol}^{-1} \mathrm{~K}^{-1}\right)\right)\end{array}$} & \multicolumn{4}{|c|}{$\Delta G^{0}\left(\mathrm{~kJ} \mathrm{~mol}^{-1}\right)$} & \multirow[b]{2}{*}{ Fitted equation } & \multirow[b]{2}{*}{$R^{2}$} \\
\hline & & & $298 \mathrm{~K}$ & $308 \mathrm{~K}$ & $318 \mathrm{~K}$ & $328 \mathrm{~K}$ & & \\
\hline 250 & 8.56 & 30.84 & -0.63 & -0.94 & -1.25 & -1.56 & $\ln K_{\mathrm{d}}=-1029.15 / T+3.71$ & 0.9814 \\
\hline
\end{tabular}

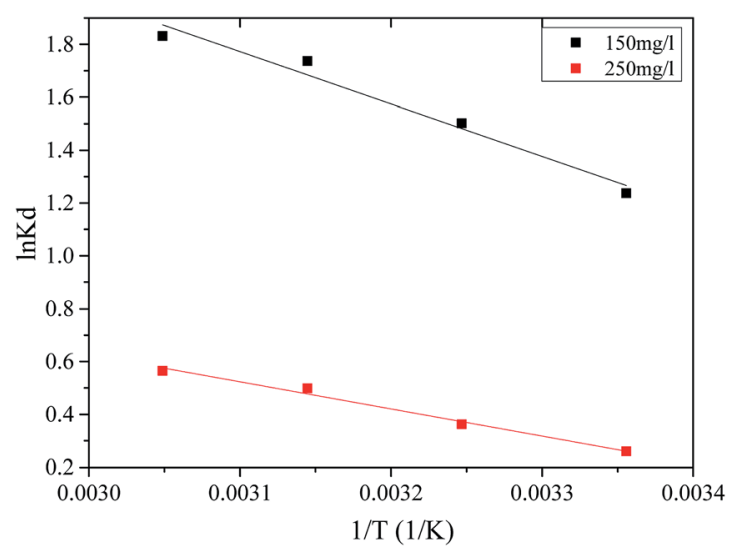

Fig. 8 Fitted curve of thermodynamics parameters for MB adsorption on the prepared MAC.

nature. The positive value of $\Delta S^{0}$ indicated that randomness at the solid/liquid interface and the degree of freedom of the adsorbed species, $\mathrm{MB}$, increased during the adsorption process. The negative values of $\Delta G$, and the positive values of $\Delta H^{0}$ and $\Delta S^{0}$ were similar to most of the processes of adsorption involving activated carbon. ${ }^{41,67}$

3.2.3 Adsorption kinetics. The adsorption kinetics of $\mathrm{MB}$ on the prepared MAC were investigated using pseudo-firstorder, pseudo-second-order and intraparticle diffusion. The integral representations of the models are shown as eqn (15)(17). The fitted curves of the pseudo-first-order models and pseudo-second-order models are shown in Fig. 9A, a, B and b. The specific fitting parameters are displayed in Table 5.

As shown in Table 5, the value of $q_{\mathrm{e}}$ calculated using the pseudo-first-order kinetic equation was much smaller than the value of the equilibrium adsorption capacity $\left(q_{\exp }\right)$ obtained from the experiment, while the value of $q_{\mathrm{e}}$ calculated using the pseudo-second-order kinetic equation was similar to $q_{\text {exp }}$. This means that the pseudo-first-order kinetic equation did not fit the absorption process of MB on the MAC well compared with the pseudo-second-order kinetic equation. Moreover, the correlation coefficient $\left(R^{2}\right)$ for the pseudo-second-order kinetic equation was almost 0.999 , greater than that obtained for the pseudo-first-order kinetic equation, which also indicated that the pseudo-second-order kinetic equation better fitted the absorption process of MB on the MAC. In addition, the amounts of adsorption of MB at the initial concentration of $250 \mathrm{mg} \mathrm{L}^{-1}$ on the MAC fitted using the pseudo-second-order kinetic equation were $136.612,147.058,149.925$ and $151.745 \mathrm{mg} \mathrm{g}^{-1}$, which were close to the measured values of $139.758,143.731$,
153.839 and $159.205 \mathrm{mg} \mathrm{g}^{-1}$, further proving this conclusion. The adsorption amounts obtained from the pseudo-secondorder kinetic equation for $\mathrm{MB}$ at the initial concentration of $150 \mathrm{mg} \mathrm{L}^{-1}$ were also close to the measured values. Thus, the absorption of MB on the prepared MAC conformed to the pseudo-second-order kinetics model to describe the adsorption kinetics data for the entire sorption period. Furthermore, these results suggested that the pseudo-second-order adsorption mechanism was predominant. The pseudo-first-order kinetic equation was more suited to describing the kinetics of the initial stage, and the application process had some limitations, while the pseudo-second-order kinetic equation contained the complete adsorption processes, such as membrane diffusion, surface adsorption, internal diffusion, and so forth, and was more suitable for the adsorption process.

The intra-particle diffusion model can be useful for identifying the adsorption pathways and adsorption mechanisms and predicting the rate-controlling step. In a solid-liquid sorption process, adsorbate transfer is often characterized by film diffusion (also known as external diffusion), surface diffusion, and pore diffusion, or combined surface and pore diffusion. In short, if a plot of $q_{\mathrm{t}}$ against $t^{0.5}$ is linear and passes through the origin, the adsorption is entirely governed by intra-particle diffusion. In contrast, if the intra-particle diffusion plot gave multiple linear regions, then the adsorption process is controlled by a multistep mechanism.

In order to identify the adsorption mechanism of $\mathrm{MB}$ on the prepared MAC, the adsorption kinetics experimental data for MB adsorption on the prepared MAC were fitted to an intraparticle diffusion model, and it was determined whether the intra-particle diffusion was the rate-controlling step of the adsorption process. The processing results are shown in Fig. 9C and $\mathrm{c}$ and Table 6. It can be seen from Fig. 9C and $\mathrm{c}$ that the adsorption process of MB on the prepared MAC exhibited a multilevel linear relationship, and the adsorption capacity increased rapidly with time at the beginning, and then decreased gradually to the dynamic equilibrium. This suggested that the adsorption process was influenced by multiple diffusion steps. The diffusion adsorption process of $\mathrm{MB}$ on the prepared MAC can be described in three stages. The first stage is the rapid diffusion stage $\left(k_{\mathrm{d} 1}\right.$ is the largest among $k_{\mathrm{d} 1}, k_{\mathrm{d} 2}$ and $\left.k_{\mathrm{d} 3}\right)$. The MB molecules are rapidly transported from the bulk liquid phase and accumulate at the external surface of the prepared MAC through a hydrodynamic boundary layer or film, known as "film diffusion" (also known as external diffusion) at a high adsorption rate. The second stage involves the surface diffusion of $\mathrm{MB}$ molecules from the exterior surface of the 

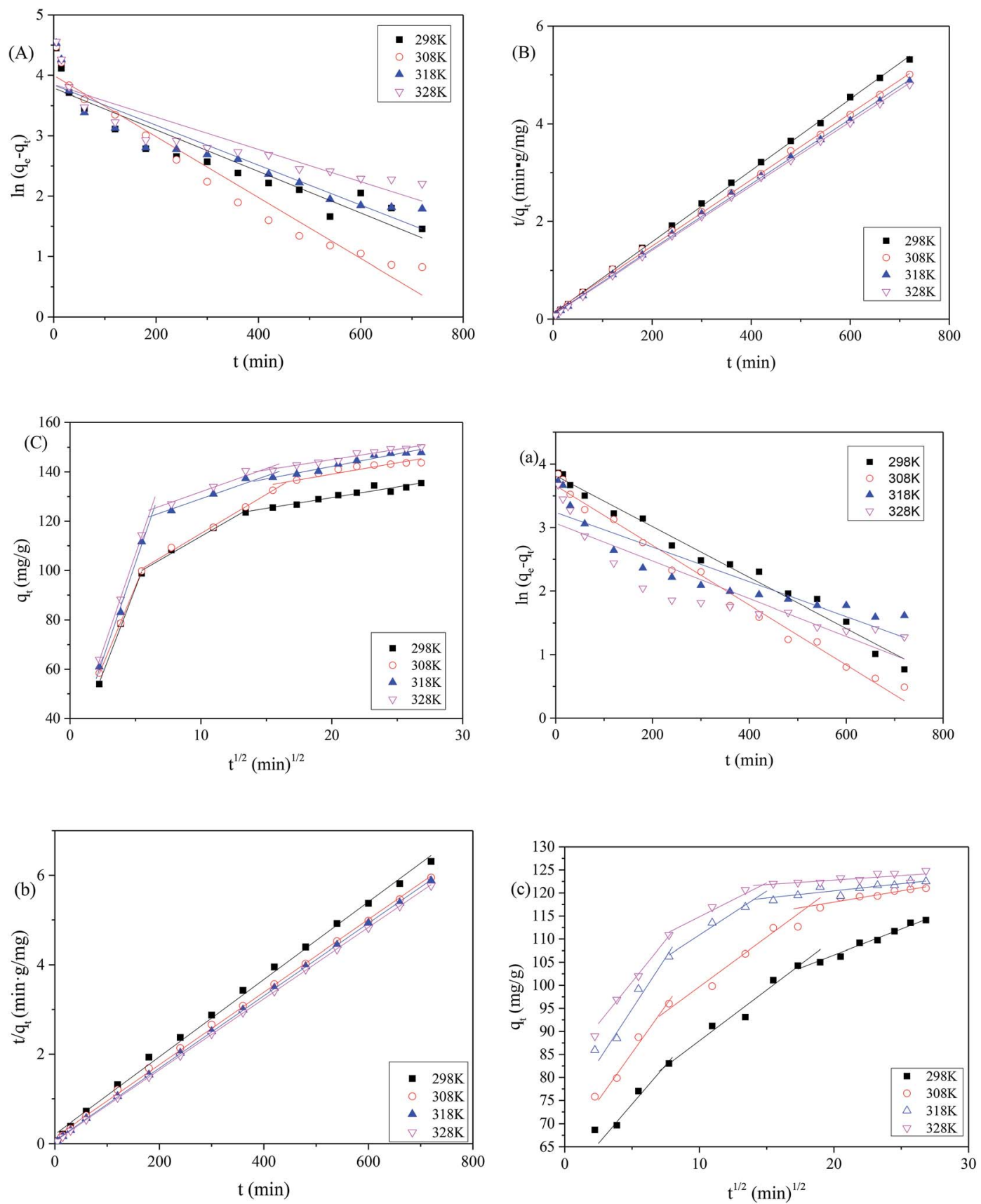

Fig. 9 (A) Pseudo-first-order kinetic model; (B) pseudo-second-order kinetic model; and (C) intraparticle diffusion model for the adsorption of MB on MAC at the initial concentration of $250 \mathrm{mg} \mathrm{L;} \mathrm{and} \mathrm{(a)} \mathrm{pseudo-first-order} \mathrm{kinetic} \mathrm{model;} \mathrm{(b)} \mathrm{pseudo-second-order} \mathrm{kinetic} \mathrm{model;} \mathrm{and} \mathrm{(c)}$ intraparticle diffusion model for the adsorption of MB on MAC at the initial concentration of $150 \mathrm{mg} \mathrm{L}^{-1}$.

prepared MAC into the pores of the prepared MAC, along the pore-wall surfaces, or both, and is known as "intraparticle diffusion", which is a slow diffusion process in particles $\left(k_{\mathrm{d} 3}<\right.$ $\left.k_{\mathrm{d} 2}<k_{\mathrm{d} 1}\right)$. In the third stage, the adsorbate MB molecules are adsorbed onto the prepared MAC internal pore surface and sorption (chemisorption) occurs, during the reaction the mass transfer resistance increases owing to the decrease of the active sites of the MAC, and the boundary layer influence increases ( $C$ value increases) when the $\mathrm{MB}$ molecules continue to interact with the active sites of the MAC, and more and more of the active sites of the MAC are occupied, the diffusion rate decreases, and the MB molecules distribution between the prepared MAC and liquid phase $\mathrm{MB}$ aqueous liquid reaches equilibrium, and the adsorption amount does not increase gradually. It can be seen from Table 6 that the three stages of the adsorption curves of MB molecules on the prepared MAC showed a good linear relationship $\left(R^{2}>0.9\right)$, but did not pass through the origin, which indicates that the adsorption process of MB molecules on the MAC was controlled by a multistep mechanism, the pore diffusion process was the rate-controlling 
Table 5 The kinetic parameters for the adsorption of MB on the prepared MAC

\begin{tabular}{|c|c|c|c|c|c|c|c|c|}
\hline \multirow{3}{*}{150} & 308 & 122.672 & 4.7 & 38.915 & 0.985 & 4.770 & 123.153 & 0.999 \\
\hline & 318 & 127.532 & 2.7 & 25.508 & 0.824 & 9.844 & 123.457 & 0.999 \\
\hline & 328 & 128.399 & 3.0 & 21.490 & 0.804 & 12.074 & 125.470 & 0.999 \\
\hline & 318 & 153.839 & 3.3 & 46.475 & 0.865 & 4.407 & 149.925 & 0.999 \\
\hline & 328 & 159.205 & 2.7 & 46.849 & 0.804 & 4.854 & 151.745 & 0.999 \\
\hline
\end{tabular}

Table 6 Parameters of the intraparticle diffusion model for the adsorption of MB on the prepared MAC

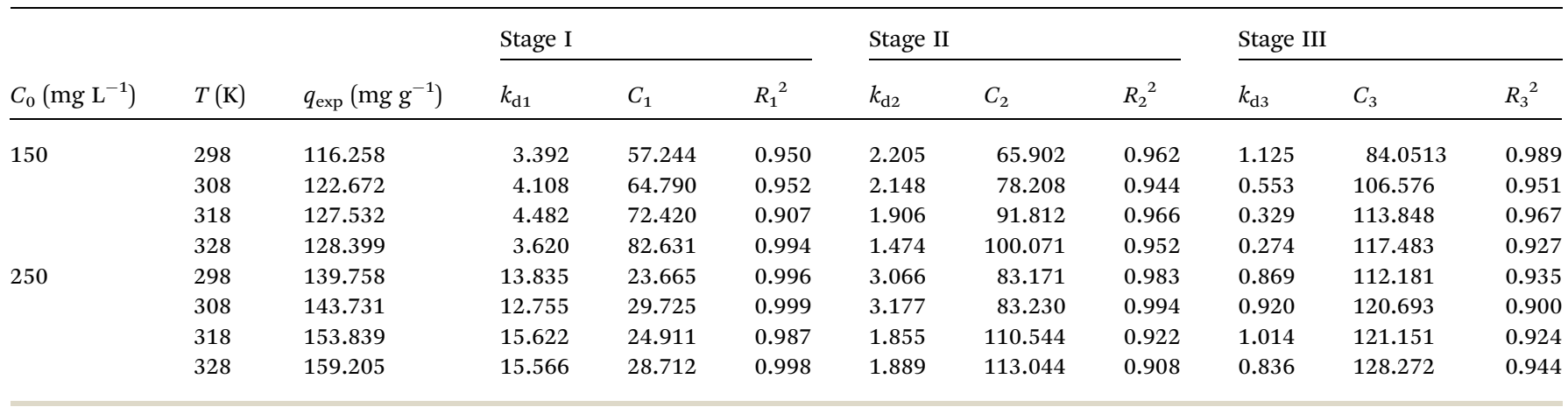

step of the adsorption process. However, the adsorption process was also affected by film diffusion and surface adsorption.

3.2.4 Adsorption mechanism of MB on the prepared MAC. The structural diagram of $\mathrm{MB}$, and the FTIR and TEM spectra of the prepared MAC before and after MB adsorption are exhibited in Fig. 10. Based on the results described in Section 3.1.3, the surface of MAC has some oxygen-containing functional groups which are confirmed by the presence of the characteristic absorption peaks at $3133 \mathrm{~cm}^{-1}(-\mathrm{OH})$, $1799 \mathrm{~cm}^{-1}(\mathrm{C}=\mathrm{O})$, and $1122 \mathrm{~cm}^{-1}(\mathrm{C}-\mathrm{O})$. The FTIR spectrum (Fig. 10B) of the prepared MAC before and after MB adsorption showed that, after adsorption of $\mathrm{MB}$, the peak at $3133 \mathrm{~cm}^{-1}$ remained unchanged but weakened, the peak at $3298 \mathrm{~cm}^{-1}$ intensified, which indicated that hydrogen bonding may not be an important process for $\mathrm{MB}$ adsorption onto $\mathrm{MAC}^{68}$. However, some functional groups in $\mathrm{MB}$, such as the peaks at $3298 \mathrm{~cm}^{-1}$ for the aromatic ring $\mathrm{C}-\mathrm{H}, 2899 \mathrm{~cm}^{-1}$ for the methyl C-H, 1735 and $1719 \mathrm{~cm}^{-1}$ for $\mathrm{C}-\mathrm{S}, 1558 \mathrm{~cm}^{-1}$ for the benzene aromatic ring, $984 \mathrm{~cm}^{-1}$ for the $\mathrm{C}-\mathrm{H}$ in-plane bending vibration, and $557 \mathrm{~cm}^{-1}$ for $\mathrm{C}-\mathrm{S}-\mathrm{C}$ were found in the FTIR spectrum (Fig. 10B) of MAC after MB adsorption. This suggested that $\mathrm{MB}$ was adsorbed onto the MAC surface or channel. Compared with the FTIR spectra of MAC, a new absorption peak at $1558 \mathrm{~cm}^{-1}$ can be clearly observed, and the peak at $1400 \mathrm{~cm}^{-1}$ is strengthened in the FTIR spectra of MAC after $\mathrm{MB}$ adsorption, which can be assigned to the vibration of the aromatic ring and the $\mathrm{C}-\mathrm{N}$ bond for $\mathrm{MB},{ }^{\mathbf{6 8}}$ which indicated that MB has been anchored on the surface of MAC during the adsorption. It should be noted that the peaks associated with the $\mathrm{C}-\mathrm{O}$ and $\mathrm{CH}$ for MAC seem to be broadened and show a significant decrease in intensity after $\mathrm{MB}$ adsorption. This can be explained by the following considerations: (i) MB is a kind of cationic dye which can be adsorbed easily by electrostatic forces on negatively charged surfaces. (ii) MB is also an ideally planar molecule and therefore can be easily absorbed onto MAC by $\pi-\pi$ stacking interactions between the aromatic backbone of MB and the hexagonal skeleton of MAC, which may lead to weakening of the intensity of $=\mathrm{CH}$ in MAC. ${ }^{68}$

Fig. 10C-F shows the TEM images of MAC after MB adsorption. Some pores are loaded and the surface of MAC shows some dispersion, which can be seen in Fig. 10C (magnification $50000 \times$ ), which could be the absorption of $\mathrm{MB}$ on the surface of MAC and in its pores. Some pores and the layer-like porous structure of MAC were almost filled, which is shown in Fig. 10D (magnification $25000 \times$ ) and Fig. 10E (magnification $50000 \times$ ). The magnetic materials were half embedded in the interior or the surface of a hole, which is shown in Fig. 10D (magnification $25000 \times$ ) and Fig. 10F (magnification $60000 \times$ ).

The XPS characterizations endow us with the ability to evaluate the roles that various organic functional groups and ferromagnetism played in the absorption of $\mathrm{MB}$ on the surface of MAC. The peaks in the XPS survey of MAC before and after 
(A)

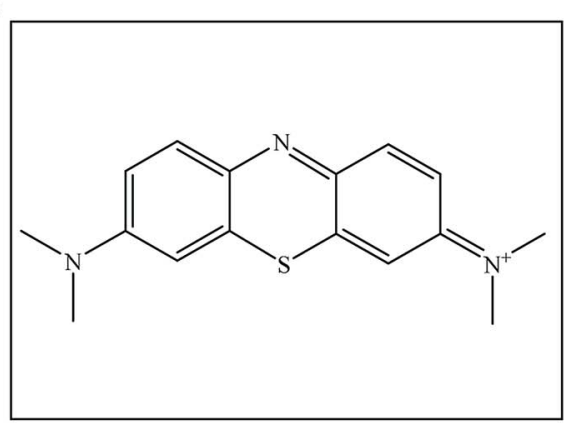

(B)

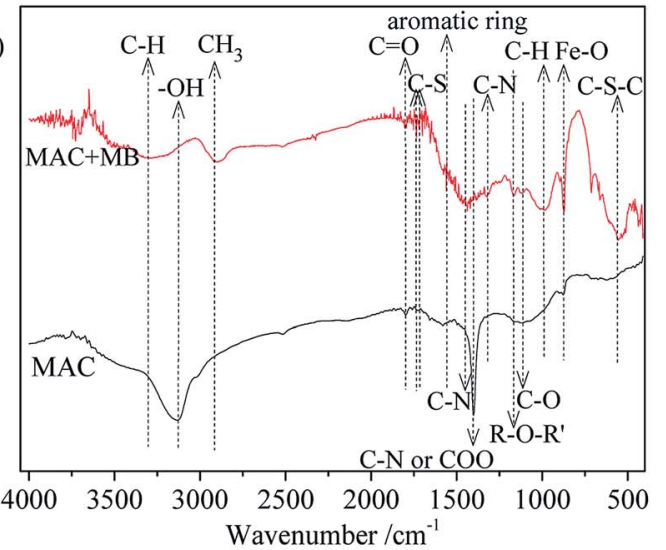

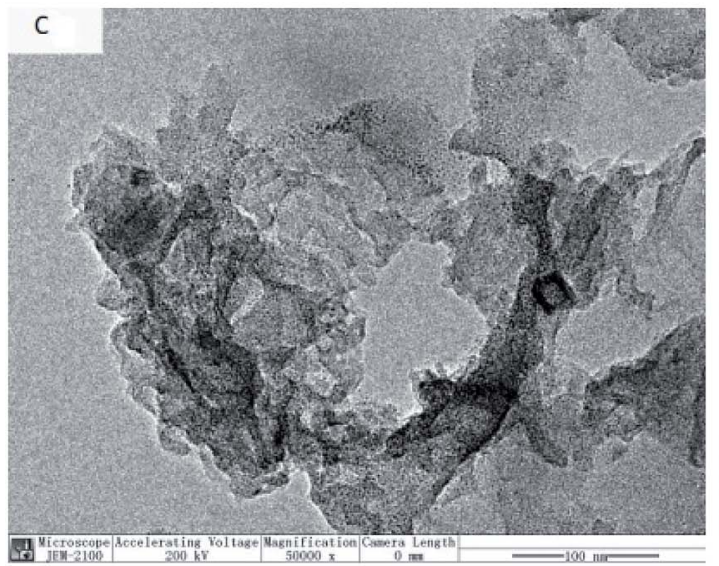
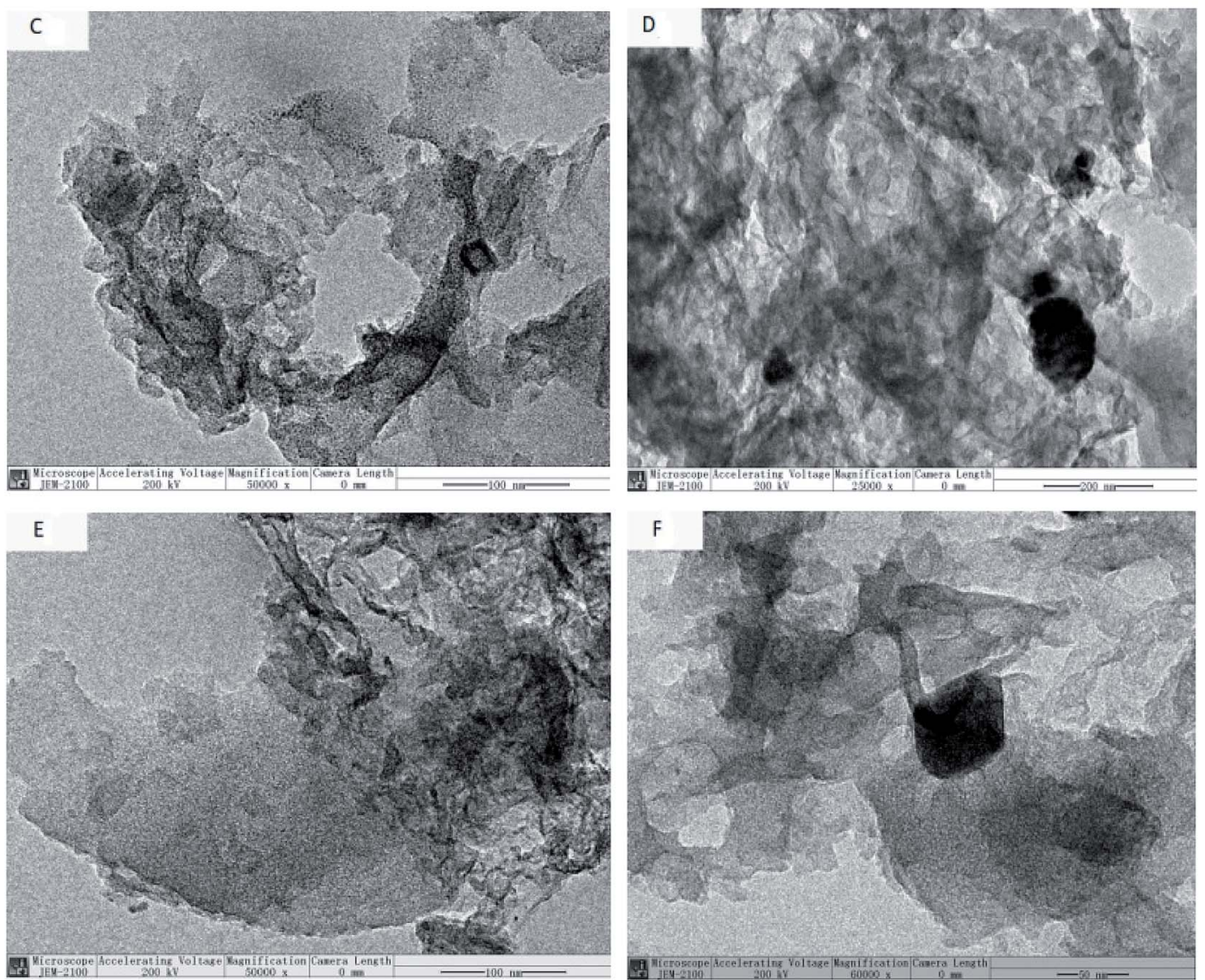

Fig. 10 (A) Structure diagram of methylene blue, (B) FTIR spectrum, (C-F) TEM image of the prepared MAC before and after MB adsorption.

MB adsorption at 283.85, 400.09, 530.74 and $710.77 \mathrm{eV}$ as shown in Fig. 11a responded to $\mathrm{C} 1 \mathrm{~s}, \mathrm{~N} 1 \mathrm{~s}, \mathrm{O} 1 \mathrm{~s}$ and $\mathrm{Fe} 2 \mathrm{p}$, and the peaks at 163.86, 199.94, 284.14, 399.16, 531.07 and $710.90 \mathrm{eV}$ responded to $\mathrm{S} 2 \mathrm{p}, \mathrm{Cl} 2 \mathrm{p}, \mathrm{C} 1 \mathrm{~s}, \mathrm{~N} 1 \mathrm{~s}, \mathrm{O} 1 \mathrm{~s}$ and Fe $2 \mathrm{p}$ (shown in Fig. 11b). It can be seen that the peaks of $\mathrm{S} 2 \mathrm{p}(163.86 \mathrm{eV}), \mathrm{Cl} 2 \mathrm{p} 1$ (199.94 eV) occurred after MB adsorption, and that the $\mathrm{N} 1 \mathrm{~s}$ (399.16 eV) intensity was higher after $\mathrm{MB}$ adsorption. The elements S 2p (163.86 eV), Cl 2p1 (199.94 eV) and N 1s (399.16 $\mathrm{eV}$ ) existed in $\mathrm{MB}$, indicating that $\mathrm{MB}$ was adsorbed onto the MAC. As for the $\mathrm{C} 1 \mathrm{~s}$ peaks, it was found from Fig. 11c and $\mathrm{d}$ that there were some shifts in the corresponding peaks before and after $\mathrm{MB}$ adsorption, $\mathrm{C}=\mathrm{C}(283.819 \mathrm{eV}), \mathrm{C}-\mathrm{C}(285.332 \mathrm{eV}), \mathrm{C}=\mathrm{O}$
(287.708 eV) shifted to $\mathrm{C}=\mathrm{C}$ or $\mathrm{C}-\mathrm{C}$ (aromatic rings) (284.073 $\mathrm{eV}), \mathrm{C}-\mathrm{OR}(285.467 \mathrm{eV}), \mathrm{C}-\mathrm{Cl}$ or $\mathrm{C}=\mathrm{O}(287.44 \mathrm{eV}) .{ }^{69,70}$ As for the $\mathrm{O} 1 \mathrm{~s}$ peaks, it was found from Fig. 11e and $\mathrm{f}$ that there was little change in the corresponding peak position before and after $\mathrm{MB}$ adsorption. For Fe 2p, as seen in Fig. $11 \mathrm{~g}$ peaks at 710.77 , $715.95,724.14$ and $728.27 \mathrm{eV}$ were observed before $\mathrm{MB}$ adsorption, and changed to $\mathrm{Fe}^{2+} 2 \mathrm{p}_{3 / 2}(709.923 \mathrm{eV}), \mathrm{Fe}^{3+} 2 \mathrm{p}_{3 / 2}$ $(711.375 \mathrm{eV}),{ }^{71} \mathrm{Fe}^{2+}(719.420 \mathrm{eV}), \mathrm{Fe}^{2+} 2 \mathrm{p}_{3 / 2}(723.669 \mathrm{eV})$, and $\mathrm{F}^{\mathrm{e} 3+} 2 \mathrm{p}_{3 / 2}(725.683 \mathrm{eV})^{72}$ after MB adsorption as seen in Fig. 11h. As for $\mathrm{N} \mathrm{1s}, \mathrm{NH}_{2}(399.6728 \mathrm{eV}),{ }^{69}$ is exhibited in Fig. 11i before MB adsorption, as N-H or -CO-NH- $(399.118 \mathrm{eV}),{ }^{73,74}$ and a new peak (401.615 eV) appeared, which was either $\mathrm{N}^{+}$binding in 

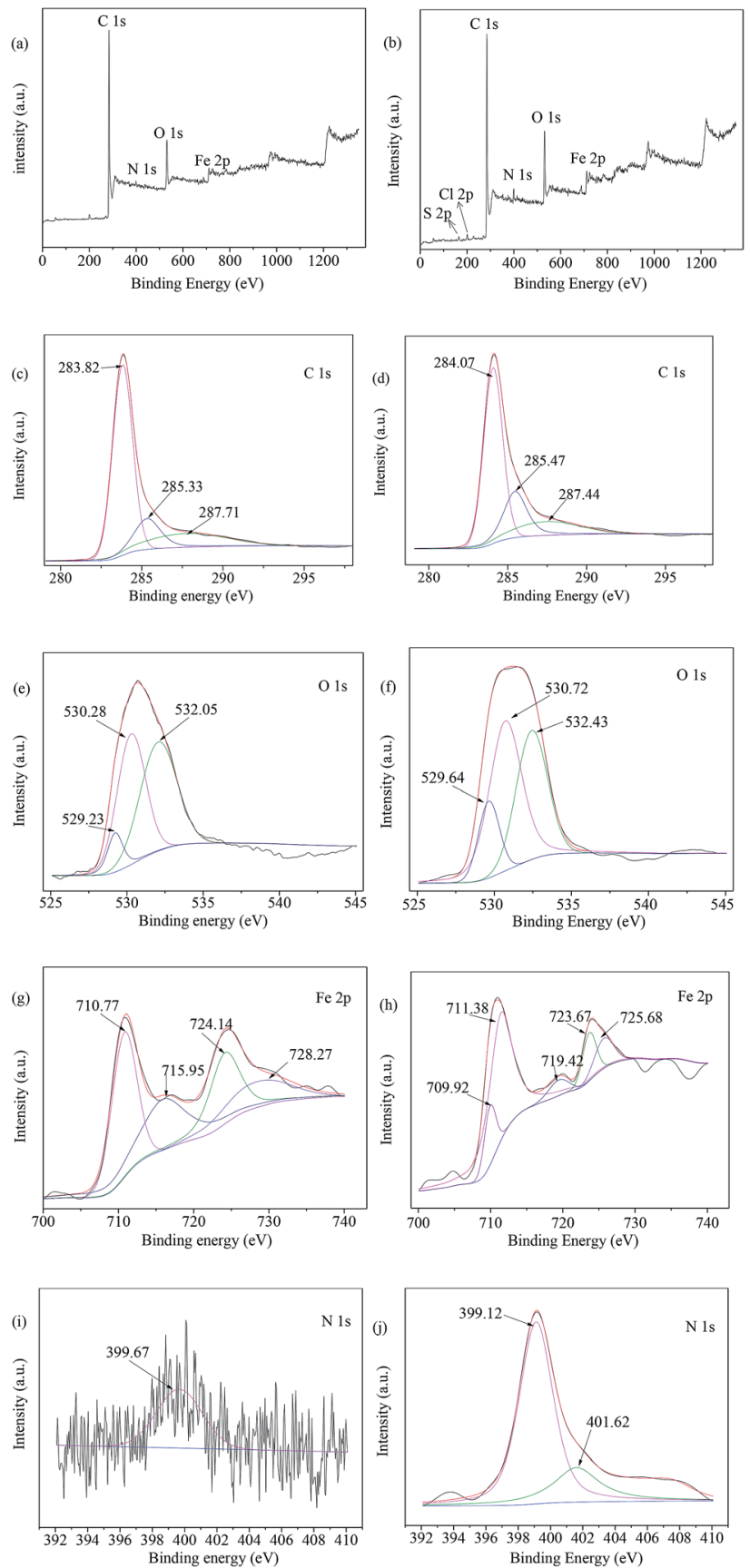

Fig. 11 XPS survey of MAC (a) before; and (b) after MB adsorption; $C$ 1s (c) before; and (d) after MB adsorption; $O$ 1s (e) before; and ( $f$ ) after MB adsorption; Fe $2 \mathrm{p}(\mathrm{g})$ before; and (h) after MB adsorption; $\mathrm{N}$ 1s (i) before; and (j) after MB adsorption.

methylene blue or $\mathrm{CO}-\mathrm{N}\left(\mathrm{CH}_{3}\right)$ formed by $\mathrm{N}$ and $\mathrm{COOH}$ binding; in other words, $-\mathrm{CO}-\mathrm{NH}_{3}{ }^{+}$or $\mathrm{N}^{+}(401.615 \mathrm{eV})^{73,75}$ existed in Fig. $11 \mathrm{j}$ after $\mathrm{MB}$ adsorption, this meant that the $\mathrm{MB}$ was adsorbed onto MAC by an interaction between the $\mathrm{N}^{+}$of $\mathrm{MB}$ and $-\mathrm{COOH}$ of MAC.

\section{Conclusions}

Eucalyptus wood-based MAC was prepared successfully by single-step carbonization activation magnetization with $\mathrm{FeCl}_{3}$ as follows: the mass ratio of $\mathrm{FeCl}_{3}$ to eucalyptus sawdust was $2: 1,20.0 \mathrm{~g}$ of eucalyptus sawdust was mixed with $50 \mathrm{~mL}$ of $\mathrm{FeCl}_{3}$ aqueous solution and maintained for $24 \mathrm{~h}$, before being dried overnight and undergoing a one-step carbonated activation for $75 \mathrm{~min}$ at $700{ }^{\circ} \mathrm{C}$. The iodine number, MB adsorption and phenol adsorption of the prepared MAC were 473.14, 228.22 and $70.90 \mathrm{mg} \mathrm{g}^{-1}$, respectively. The BET surface, average pore diameter and pore volume were $645.23 \mathrm{~m}^{2} \mathrm{~g}^{-1}$, $2.71 \mathrm{~nm}$ and $0.44 \mathrm{~cm}^{3} \mathrm{~g}^{-1}$, respectively. The prepared MAC were magnetic, and could be separated by a magnetic separator with the following magnetic parameters, a $H_{\mathrm{c}}$ of 108.51 Oe, $M_{\mathrm{S}}$ of $30.37 \mathrm{emu} \mathrm{g}^{-1}$ and $M_{\mathrm{r}}$ of $2.46 \mathrm{emu} \mathrm{g}^{-1}$; there were $\mathrm{OH}, \mathrm{C}-\mathrm{O}, \mathrm{C}=\mathrm{O}, \mathrm{C}=\mathrm{C}, \mathrm{COO}, \mathrm{C}-\mathrm{N}$, and $\mathrm{Fe}-\mathrm{O}$ groups on the MAC surface, and $\mathrm{Fe}_{3} \mathrm{O}_{4}$ existed in the pores and surfaces of the MAC. The prepared MAC was utilized to adsorb MB in an aqueous solution, the adsorption followed the Langmuir isotherm and Dubinin-Radushkevich isotherm model. The adsorption process was a spontaneous, endothermic chemisorption process, followed by the pseudo-second-order model, and the adsorption process was influenced by multiple diffusion steps. The pore diffusion process was the rate-controlling step of the adsorption process, however, the adsorption process was also affected by film diffusion and surface adsorption. Eucalyptus wood-based MAC was found to be efficient for MB adsorption, and can be easily separated and recovered using an external magnetic field. MAC could be used as a potential adsorbent for the treatment of organic pollutant wastewater.

\section{Conflicts of interest}

There are no conflicts to declare.

\section{Acknowledgements}

The authors are grateful for financial support from the National Natural Science Foundation of China (31660183). This project was also supported by the Guangxi Natural Science Foundation (2015GXNSFAA139023), and the Dean Project of Guangxi Key Laboratory of Petrochemical Resource Processing and Process Intensification Technology (2018K010).

\section{References}

1 Suhas, V. K. Gupta, P. J. Carrott, R. Singh, M. Chaudhary and S. Kushwaha, Bioresour. Technol., 2016, 216, 1066-1076.

2 M. Yu, Y. Han, J. Li and L. Wang, Chem. Eng. J., 2017, 317, 493-502.

3 M. Sevilla and R. Mokaya, Energy Environ. Sci., 2014, 7, 125128.

4 Q. Ma, Y. Yu, M. Sindoro, A. G. Fane, R. Wang and H. Zhang, Adv. Mater., 2017, 29, 1605361.

5 F. Marrakchi, M. J. Ahmed, W. A. Khanday, M. Asif and B. H. Hameed, Int. J. Biol. Macromol., 2017, 98, 233-239.

6 W. Hao, E. Björkman, M. Lilliestråle and N. Hedin, Appl. Energy, 2013, 112, 526-532. 
7 X. Feng, B. Fu, S. Piao, S. Wang, P. Ciais, Z. Zeng, Y. Lü, Y. Zeng, Y. Li, X. Jiang and B. Wu, Nat. Clim. Change, 2016, 6, 1019-1022.

8 M. Rafatullah, O. Sulaiman, R. Hashim and A. Ahmad, J. Hazard. Mater., 2010, 177, 70-80.

9 T. L. Silva, A. Ronix, O. Pezoti, L. S. Souza, P. K. T. Leandro, K. C. Bedin, K. K. Beltrame, A. L. Cazetta and V. C. Almeida, Chem. Eng. J., 2016, 303, 467-476.

10 M. G. K. D. F. Nasiri Azad and S. H. M. R. M. Montazerozohori., RSC Adv., 2016, 6, 1978019791.

11 J. Chang, J. Ma, Q. Ma, D. Zhang, N. Qiao, M. Hu and H. Ma, Appl. Clay Sci., 2016, 119, 132-140.

12 A. M. Aljeboree, A. N. Alshirifi and A. F. Alkaim, Arabian J. Chem., 2017, 10, S3381-S3393.

13 H. Cherifi, B. Fatiha and H. Salah, Appl. Surf. Sci., 2013, 282, 52-59.

14 Z. C. Kadirova, K. Katsumata, T. Isobe, N. Matsushita, A. Nakajima and K. Okada, Appl. Surf. Sci., 2013, 284, 72-79. 15 Y. Gokce and Z. Aktas, Appl. Surf. Sci., 2014, 313, 352-359.

16 E. Pargoletti, V. Pifferi, L. Falciola, G. Facchinetti, A. Re Depaolini, E. Davoli, M. Marelli and G. Cappelletti, Appl. Surf. Sci., 2019, 472, 118-126.

17 T. N. V. de Souza, S. M. L. de Carvalho, M. G. A. Vieira, M. G. C. Da Silva and D. D. S. B. Brasil, Appl. Surf. Sci., 2018, 448, 662-670.

18 Q. Liu, T. Zheng, N. Li, P. Wang and G. Abulikemu, Appl. Surf. Sci., 2010, 256, 3309-3315.

19 D. Liu, W. Yuan, P. Yuan, W. Yu, D. Tan, H. Liu and H. He, Appl. Surf. Sci., 2013, 282, 838-843.

20 Z. Zhang, Z. Zhang, Y. Fernández, J. A. Menéndez, H. Niu, J. Peng, L. Zhang and S. Guo, Appl. Surf. Sci., 2010, 256, 2569-2576.

21 Z. Han, B. Sani, J. Akkanen, S. Abel, I. Nybom, H. K. Karapanagioti and D. Werner, J. Hazard. Mater., 2015, 286, 41-47.

22 R. S. Ribeiro, A. M. T. Silva, J. L. Figueiredo, J. L. Faria and H. T. Gomes, Appl. Catal., B, 2016, 187, 428-460.

23 H. Li, Y. Li, Y. Zhang, C. Liang, H. Wang, B. Li, D. Adair and Z. Bakenov, Nanoscale Res. Lett., 2016, 11, 432-440.

24 N. M. Mubarak, A. Kundu, J. N. Sahu, E. C. Abdullah and N. S. Jayakumar, Biomass Bioenergy, 2014, 61, 265-275.

25 J. Georgin, G. L. Dotto, M. A. Mazutti and E. L. Foletto, J. Environ. Chem. Eng., 2016, 4, 266-275.

26 S. Zhang, L. Tao, Y. Zhang, Z. Wang, G. Gou, M. Jiang, C. Huang and Z. Zhou, Powder Technol., 2016, 295, 152-160.

27 D. Chen, X. Chen, J. Sun, Z. Zheng and K. Fu, Bioresour. Technol., 2016, 216, 629-636.

28 Z. A. Ghani, M. S. Yusoff, N. Q. Zaman, M. F. M. A. Zamri and J. Andas, Waste Manag., 2017, 62, 177-187.

29 A. L. Cazetta, O. Pezoti, K. C. Bedin, T. L. Silva, A. Paesano Junior, T. Asefa and V. C. Almeida, ACS Sustainable Chem. Eng., 2016, 4, 1058-1068.

30 G. Venkatesan, U. Senthilnathan and S. Rajam, Clean Technol. Environ., 2014, 16, 195-200.

31 C. Chen, P. Zhao, Z. Li and Z. Tong, Desalin. Water Treat., 2016, 57, 12572-12584.
32 C. Chen, X. Li, Z. Tong, Y. Li and M. Li, Appl. Surf. Sci., 2014, 315, 203-211.

33 C. Liu, Y. Sun, D. Wang, Z. Sun, M. Chen, Z. Zhou and W. Chen, Ultrason. Sonochem., 2017, 34, 142-153.

34 Z. Sun, C. Liu, Z. Cao and W. Chen, Ultrason. Sonochem., 2018, 44, 86-96.

35 G. Z. Kyzas, E. A. Deliyanni and N. K. Lazaridis, J. Colloid Interface Sci., 2014, 430, 166-173.

36 X. Peng, D. Huang, T. Odoom-Wubah, D. Fu, J. Huang and Q. Qin, J. Colloid Interface Sci., 2014, 430, 272-282.

37 P. Wang, M. Cao, C. Wang, Y. Ao, J. Hou and J. Qian, Appl. Surf. Sci., 2014, 290, 116-124.

38 H. Deng, J. Lu, G. Li, G. Zhang and X. Wang, Chem. Eng. J., 2011, 172, 326-334.

39 Y. Zhou, X. Liu, L. Tang, F. Zhang, G. Zeng, X. Peng, L. Luo, Y. Deng, Y. Pang and J. Zhang, J. Hazard. Mater., 2017, 333, 80-87.

40 Y. L. Yu Liu, Sep. Purif. Technol., 2008, 61, 229-242.

41 A. L. Cazetta, A. M. M. Vargas, E. M. Nogami, M. H. Kunita, M. R. Guilherme, A. C. Martins, T. L. Silva, J. C. G. Moraes and V. C. Almeida, Chem. Eng. J., 2011, 174, 117-125.

42 K. C. Bedin, I. P. A. F. Souza, A. L. Cazetta, L. Spessato, A. Ronix and V. C. Almeida, J. Mol. Liq., 2018, 269, 132-139.

43 M. A. Islam, M. J. Ahmed, W. A. Khanday, M. Asif and B. H. Hameed, Ecotoxicol. Environ. Saf., 2017, 138, 279-285. 44 A. Heidari, H. Younesi, A. Rashidi and A. Ghoreyshi, J. Taiwan Inst. Chem. Eng., 2014, 45, 579-588.

45 S. Guo, J. Peng, W. Li, K. Yang, L. Zhang, S. Zhang and H. Xia, Appl. Surf. Sci., 2009, 255, 8443-8449.

46 L. Mouni, L. Belkhiri, J. Bollinger, A. Bouzaza, A. Assadi, A. Tirri, F. Dahmoune, K. Madani and H. Remini, Appl. Clay Sci., 2018, 153, 38-45.

47 J. Song, X. Wang, J. Huang, J. Ma, X. Wang, H. Wang, R. Ma, P. Xia and J. Zhao, Electrochim. Acta, 2016, 222, 1-11.

48 D. C. Jiles, Acta Mater., 2003, 51, 5907-5939.

49 O. Duman, S. Tunç, B. K. Bozoğlan and T. G. Polat, J. Alloys Compd., 2016, 687, 370-383.

50 T. A. Saleh, Naeemullah, M. Tuzen and A. Sar, Chem. Eng. Res. Des., 2017, 117, 218-227.

51 J. Luo, J. Lu, Q. Niu, X. Chen, Z. Wang and J. Zhang, Fuel, 2015, 160, 440-445.

52 G. Zeng, Y. Liu, L. Tang, G. Yang, Y. Pang, Y. Zhang, Y. Zhou, Z. Li, M. Li, M. Lai, X. He and Y. He, Chem. Eng. J., 2015, 259, 153-160.

53 X. Luo, X. Lei, X. Xie, B. Yu, N. Cai and F. Yu, Carbohydr. Polym., 2016, 151, 640-648.

54 R. Fu, Y. Liu, Z. Lou, Z. Wang, S. A. Baig and X. Xu, J. Taiwan Inst. Chem. Eng., 2016, 62, 247-258.

55 A. A. A. Tawfik and A. Saleh, J. Mol. Liq., 2017, 248, 577-585. 56 E. Kılınç, J. Magn. Magn. Mater., 2016, 401, 949-955.

57 H. S. Saroyan, D. A. Giannakoudakis, C. S. Sarafidis, N. K. Lazaridis and E. A. Deliyanni, J. Chem. Technol. Biotechnol., 2017, 92, 1899-1911.

58 C. Chen, J. Luo, W. Qin and Z. Tong, Monatsh. Chem., 2014, 145, 175-185.

59 P. Wang, M. Cao, C. Wang, Y. Ao, J. Hou and J. Qian, Appl. Surf. Sci., 2014, 290, 116-124. 
60 S. T. Danalığlu, Ş. S. Bayazit, Ö. Kerkez Kuyumcu and M. A. Salam, J. Mol. Liq., 2017, 240, 589-596.

61 Y. Liu, Y. Kang, B. Mu and A. Wang, Chem. Eng. J., 2014, 237, 403-410.

62 S. K. Theydan and M. J. Ahmed, J. Anal. Appl. Pyrolysis, 2012, 97, 116-122.

63 A. Asfaram, G. A. Mehrorang, H. B. Shaaker and G. Alireza, Ultrason. Sonochem., 2016, 32, 418-431.

64 A. A. Mir, A. A. Amooey and S. Ghasemi, J. Cleaner Prod., 2018, 170, 570-580.

65 S. T. Yang, S. Chen, Y. Chang, A. Cao and Y. Liu, J. Colloid Interface Sci., 2011, 359, 24-29.

66 P. Reddy, P. Verma and C. Subrahmanyam, J. Taiwan Inst. Chem. Eng., 2016, 58, 500-508.

67 D. Angın, T. E. Köse and U. Selengil, Appl. Surf. Sci., 2013, 280, 705-710.

68 L. Ai, C. Zhang, F. Liao, Y. Wang, M. Li, L. Meng and J. Jiang, J. Hazard. Mater., 2011, 198, 282-290.
69 W. Xie and M. Huang, Energy Convers. Manage., 2018, 159, 42-53.

70 M. Cao, P. Wang, Y. Ao, C. Wang, J. Hou and J. Qian, Chem. Eng. J., 2015, 264, 113-124.

71 S. Gao, L. Liu, Y. Tang, D. Jia, Z. Zhao and Y. Wang, J. Porous Mater., 2016, 23, 877-884.

72 K. V. M. K. Kireeti, G. Chandrakanth, M. M. Kadam and N. Jha, $R S C$ Adv., 2016, 6, 84825-84836.

73 M. Li, Y. Liu, S. Liu, G. Zeng, X. Hu, X. Tan, L. Jiang, N. Liu, J. Wen and X. Liu, J. Colloid Interface Sci., 2018, 521, 150-159.

74 A. Kumar, A. Kumar, G. Sharma, M. Naushad, F. J. Stadler, A. A. Ghfar, P. Dhiman and R. V. Saini, J. Cleaner Prod., 2017, 165, 431-451.

75 M. Mitra, M. Mahapatra, A. Dutta, J. S. D. Roy, M. Karmakar, M. Deb, H. Mondal, P. K. Chattopadhyay, A. Bandyopadhyay and N. R. Singha, J. Hazard. Mater., 2019, 369, 746-762. 